\title{
A Novel Energy Saving Operation Strategy of Multiparameter Coupling Coordinated Speed Regulation for Crushing
}

\author{
Enhua Luo $^{2}$, Wei Zhang ${ }^{1}$, Ruixin Zhang ${ }^{3}$, Yu Liu ${ }^{2,3 *}$, Xiaoming Liu ${ }^{1}$, Changlong Wang ${ }^{4}$ \\ ${ }^{1}$ School of Metallurgical and Ecological Engineering, University of Science and Technology Beijing, Beijing 100083, China \\ ${ }^{2}$ China International Engineering Consulting Corporation, Beijing 100048, China \\ ${ }^{3}$ School of Resource and Safety Engineering, China University of Mining and Technology, Beijing 100083, China \\ ${ }^{4}$ School of Civil Engineering, Hebei University of Engineering, Handan 056038, China
}

Corresponding Author Email: itvrly@163.com

https://doi.org/10.18280/acsm.440303

Received: 18 March 2020

Accepted: 3 June 2020

\section{Keywords:}

sustainable, energy saving, crushing station, multiparameter

\begin{abstract}
Energy saving is an important measure for the sustainable of opencast mining industry. However, the energy saving operation of crushing station is affected by vibration and collision in the process of open pit mining. This research aims to explore a novel strategy to reduce the high energy consumption of crushing station. Discrete element method (DEM), particle contact model and multiscale viscous particle model were used to analyse the operation process of crushing station. A multiparameter coupling coordinated speed regulation crushing strategy was proposed combined with the crusher model and simulation parameters. The practical application of this strategy in the crushing station of Shenbao energy open pit mine has been verified. The application results showed that compared with the manual operation control, the crushing efficiency of the crushing station is increased by $21.80 \%$, the powder passing rate is reduced by $53.35 \%$, and the operation energy saving of the crushing station is about $41.00 \%$. The energy saving effect of multiparameter optimization is better than that of single parameter. This research provides a new theoretical basis for energy saving operation of crushing station in open pit mine.
\end{abstract}

\section{INTRODUCTION}

Sustainable development is conducive to promoting the unity of ecological, economics and social benefits. Therefore, energy saving is the right way for the sustainable development of industrial enterprises [1-3]. Energy saving mining of openpit mine has important economic benefits, which has been widely concerned in recent years [4-7]. Energy saving in the production of open pit mining enterprises is considered as an important measure of sustainable [8-10]. Energy saving is the foundation of the survival of mining enterprises. It can reduce consumption, reduce loss, stop waste from energy consumption to production, and effectively and reasonably use energy. Crushing station is the key procedure of open pit mining operation. The working state of crushing station directly affects the energy consumption of crushing system [11-13]. Crushing tools have been used by humans for thousands of years. The theory of crushing, the design of crushing machinery, and the study of crushing processes began to be proposed back to the last century [14-16]. However, the crushing station is inevitably affected by vibration and friction in the mining production process, resulting in excessive energy consumption in the crushing process [17, 18]. It hinders indirectly the sustainable and economic benefits of opencast mining industry $[19,20]$.

One way is to use simulation to optimize the operation parameters of crushing station, and finally the purpose of energy saving of crushing system is achieved. In recent years, the optimization of important operation parameters of crushing station to improve the system energy saving has been widely studied. For example, Numbi [21] found that the optimal control of the working frequency of crusher, the energy saving of the crushing system was $30.12 \%$. Terva [22] optimized the parameters of crushing quantity of crusher, and the minimum energy required for ore crushing was approximately obtained. The maximum energy saving of this method was $18.60 \%$ when the friction coefficient was 0.65. Singh [23] used alternating power on method for motor of crushing station, and the maximum energy saving of crushing system was $15.00 \%$. Deng [24] established a quantitative relationship between energy consumption and particle size parameters of minerals after crushing by simulation. It is beneficial to energy saving of crushing system. Legendre [25] obtained the relationship between the area increment parameters of crushed minerals and energy consumption by simulation, and the energy consumption was optimized.

Predecessors optimized a single parameter variable in the crushing station, and made a certain contribution to the energy saving of the crushing station. However, the comprehensive optimization research on material size, material distribution, feeding capacity, crushing capacity, crushing completion time, material level height and tooth roll speed of the crushing station has not been realized in the aspect of improving the energy saving operation of the crushing station. This research proposed a novel scheme in order to solve this knowledge gap. A series of optimization research on crushing station system was carried out by multiparameter simultaneous simulation method in order to promote energy saving operation of 
crushing station. The energy saving operation of crushing station was analysed by DEM, particle contact model and multiscale viscous particle model. Aiming at energy saving operation of crushing station, a multiparameter coupling coordinated speed regulation crushing strategy was proposed based on load state. The research has been verified in the crushing station of Shenbao energy company, and achieved remarkable application effect and economic benefit [26]. It provides a new theoretical basis for energy saving operation of crushing station.

The paper is structured as follows. In Section 2, the methodology used in this study is analysed in detail. In Section 3 , the crusher model and multiparameter coupling coordinated speed control crushing strategy are introduced. The verification process of the actual case to the simulation results is described in detail in Section 4. Finally, the simulation results of multiparameter coupling coordinated speed regulation crushing strategy and the application effect of case verification are summarized.

\section{METHODOLOGY}

\subsection{Research route}

The Research Route is shown in the Figure 1 below.

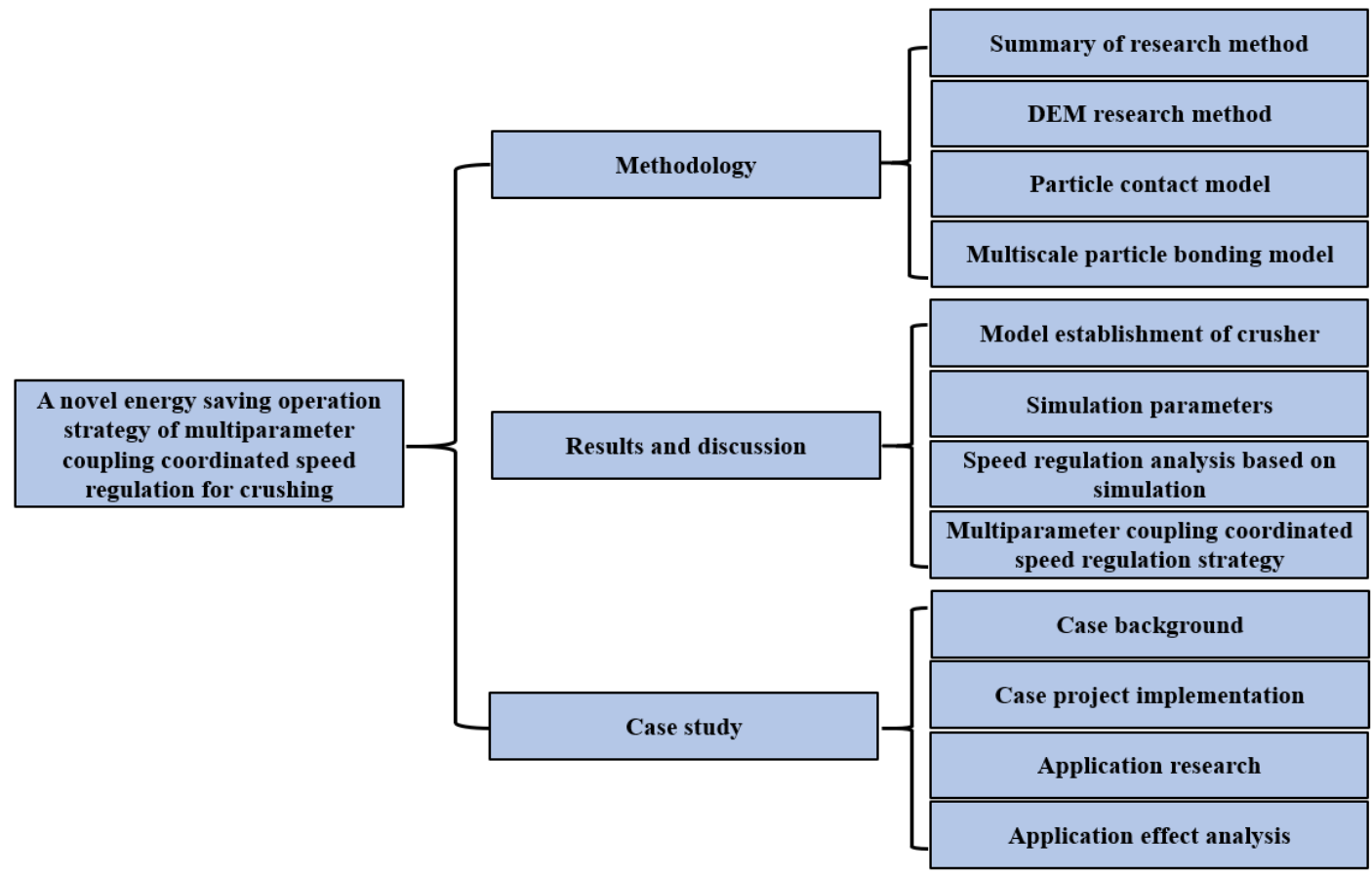

Figure 1. Research route

\subsection{Summary of research method}

Relevant research results in this field are summarized according to the current situation of open pit industry and the development of crushing station technology. The main contents of this research method are mining engineering theory, theory combined with practice, mechanical crushing technology and computer technology. The specific research methods are as follows.

(1) Mining engineering theory [27]

Mining engineering is a complex system engineering, which involves geology and engineering. The mining conditions and the interaction between mining objects and crushing technology are analysed by mining engineering theory. It provides a theoretical basis for the comprehensive optimization of energy saving operation of crushing station system.

(2) Theory combined with practice [28]

The research and application of energy saving operation of crushing station is of great significance to improve the efficient mining and stripping operation of large-scale open pit system. The multiparameter coupling coordinated speed regulation crushing strategy in crushing station is proposed combined with practice. The feasibility of the strategy is verified by practical engineering application.
(3) Mechanical crushing technology [29]

Optimization of crushing technology is an effective way to improve energy saving operation of crushing station. The DEM is a numerical simulation method specially used to solve the problem of discontinuous medium [53]. Mechanical crushing principle and DEM are used to optimize the energy saving operation of crushing station. The energy saving operation of the core component feeder and crusher in the crushing station is optimized based on the multiparameter coupling coordinated speed regulation strategy of different feed particle size distribution.

(4) Computer technology [30]

The relationship between mining energy consumption and equipment parameters is not accurate due to the complexity of mining engineering. The established mathematical model is also difficult to find the definite mathematical analytical solution through the traditional method. Therefore, mature computer simulation technology is used in order to solve the feasibility of model solution and engineering application. The simulation of crushing efficiency, powder passing rate, mechanical control parameter setting and other parameters are carried out based on different material characteristics. The established mathematical model is solved by certain calculation methods and criteria. The sensor data can be read with the help of computer language. The energy saving of 
crushing station operation is improved through the multiparameter coupling coordinated speed regulation crushing strategy.

\subsection{DEM research method}

The DEM is a novel numerical method for solving the motion laws and mechanical properties of discrete systems [31-33]. The discrete element types can be divided into two categories: particle and block according to the different geometric characteristics of the research object. The former is for the scattered objects with various particle shapes, while the latter is mainly for large minerals. The block size of minerals is connected by a set of contact bonds according to the basic principle of the DEM. Therefore, the fractal dimension of rock mechanics can be explained by the fracture of the mineral contact bond in simulation. The micro crushing of minerals is the process of producing new blocks. That is to say, the process of mineral crushing produces new fracture surface. The macroscopic fracture of minerals is the final result of the continuous development, expansion, aggregation and transfixion of internal cracks under the action of external forces. The geometric characteristics of structural evolution and the digital characteristics of physical quantity evolution show similarity in the process of micro fracture and macro fracture. Therefore, fractal theory can be used to explain the process of mineral crushing, which improves the analysis level of energy-saving operation of crushing process [34]. A natural fractal, such as a mineral, consisting of discrete bodies, defined as:

$$
N_{r}=C r^{-D}
$$

where, $N_{r}$ is the number of dispersion whose characteristic dimension is greater than $r, C$ is the material constant, $D$ is the fractal dimension of the block.

The crushing of minerals is a process of energy dissipation. Therefore, it can be assumed that there is a cubic body under the action of external force, the side length is $R_{l}$, and the strain energy it contains is $E_{r}$. Take the edge length as $R_{l}$ and set the included strain energy to $E_{r}$. First, the cube is divided into $k$ sub cubes with side length $R_{2}=R_{1} k^{-\frac{1}{3}}(k>8)$ and $P$ sub cubes are randomly selected for subdivision [35]. Second, each sub cube is subdivided into smaller cubes with side length of $R_{3}=R_{2} k^{-\frac{1}{3}}=R_{1} k^{-\frac{2}{3}}$. Repeat the process to step $n$, and so on. It is assumed that the subdivision process is the crushing process of minerals. The energy of each step is dissipated on the $P$ cube, which is independent of the $k$ - $P$-cube. In this way, the total energy decreases from the $k$ fragments with side length $R_{n}$ to the $P$ fragments with side length $R_{n+1}$. It is observed that the energy dissipation in the process of fragmentation is a fractal. The fractal dimension is as follows [36]:

$$
D=3 \frac{\log P}{\log k} \epsilon(0,3)
$$

The minerals show fractal distribution with similar characteristics in the crushing process. At present, the measurement methods of fractal distribution of mineral blocks after crushing mainly include scale-frequency relationship and fragment quality-frequency relationship. $R$ is the average scale of the broken mineral. $N$ is the number of individuals whose characteristic scale is greater than or equal to $R$. The definition of fractal extends to the continuous form as follows:

$$
N=C R^{-D}
$$

As the mineral fragmentation belongs to fractal distribution, it has the following relations according to scale-frequency:

$$
N=N_{0}\left(\frac{R}{R_{\max }}\right)^{D}
$$

where, $N_{0}$ is the number of fragments with the largest characteristic size $R_{\max }$. Another measurement method is the mass-frequency relationship:

$$
N=N_{0}\left(\frac{M}{M_{\max }}\right)^{-b}
$$

where, $N$ is the number of fragments with mass greater than or equal to $M . N_{0}$ is the number of fragments with maximum mass $M_{\max } . b$ is the mass-frequency distribution index. According to the correlation $M \infty R^{3}$ between mass and block size, the relationship between fractal dimension of block size distribution and frequency distribution index is: $\mathrm{D}=3 b$. There are the number $\left(\left(R_{1} / R_{n}\right)^{3}=(R / r)^{3}\right)$ of sub cubes with side length $r=R_{n}$ the cube with side length $R=R_{l}$. The number of cubes causing energy dissipation is $(R / r)^{D}$. The volume occupied by the energy dissipating sub cube in the fragment of size $r$ is $V_{r}=(R / r)^{D} r^{3}$. The corresponding total fragment volume is $V=R^{3}$. In this way, the ratio $E_{0}$ of the dissipative volume to the total volume is obtained as follows:

$$
E_{0}=\frac{V_{r}}{V}=\left(\frac{R}{r}\right)^{D-3}=\left(\frac{R}{r}\right)^{-\mu}
$$

If $E_{r}$ is the average dissipation energy per unit volume, it can be concluded that:

$$
E_{T} V=E_{r} V_{r}
$$

In the fragment with side length $r$, the average dissipation energy $E_{r}$ is:

$$
E_{r}=E_{T} E_{0}^{-1} \infty r^{-\mu}
$$

From the above formula, the energy input of fractal fragmentation can be obtained as follows:

$$
E_{r}=C_{f}\left(r_{2}^{D-3}-r_{l}{ }^{D-3}\right)
$$

where, $C_{f}$ is the material parameter, $r_{1}$ and $r_{2}$ are the material size before and after crushing respectively. It can be seen from the above formula that the energy consumption in the process of material crushing is mainly related to the material characteristics (the size of material before and after crushing and the degree of material crushing). It is mainly related to the fractal dimension and fracture bond from the point of view of discrete element.

The mechanical characteristics of granular materials were summarized as "Dispersion" and "Movement" by the DEM. "Dispersion" refers to dispersion of particle nature, particle size and shape. "Movement" refers to collision, fracture and breakage of particle agglomerates in motion [37]. It can be concluded that the essence of feeding link is the study of mineral shape and distribution by using the DEM to analyze the feeding and crushing process of crushing station, corresponding to the "Dispersion" in discrete element. The 
essence of fragmentation is to study the process of "Decomposition" of block minerals under the action of external forces, which corresponds to the "Movement" of discrete elements.

\subsection{Particle contact model and multiscale cohesive particle model}

\subsubsection{Particle contact model}

The DEM is used to describe the motion of particles, which is the process of contact force between particles. The contact force relationship between multiple particles must be considered. This research mainly refers to Hertz-Mindlin with bonding built-in bonding contact model, which is generally applicable to ore structure modeling. The binding bond can prevent the relative movement of particles. The bond will be destroyed, so that the mineral can be broken when the external force applied on the mineral reaches the maximum stress that the mineral can bear. The bonding model assumes that the particles are bound at a certain time $t_{s}$, and before that, the particles interact with each other through the contact model. The bonding force $F_{n}, F_{t}$ model and torque $T_{n}, T_{t}$ models are as shown in Eq. (10). The bonding force and torque increase gradually with time step from zero.

$$
\left\{\begin{array}{l}
F_{n}=-v_{n} S_{n} A t \\
F_{t}=-v_{t} S_{t} A t \\
T_{n}=-\omega_{n} S_{t} J t \\
T_{t}=-\omega_{t} S_{n} \frac{J}{2} t
\end{array}\right.
$$

where, $A$ is the contact area. $A=\pi R_{B}^{2}\left(R_{B}\right.$ is the bonding radius). $t$ is time. $S_{n}$ is the normal stiffness. $S_{t}$ is the tangential stiffness. $J$ is $J=\frac{1}{2} \pi R_{B}{ }^{4} . \omega_{n}$ is the normal angular velocity of the particle. $\omega_{t}$ is the tangential angular velocity of particles. $v_{n}$ is the normal velocity of the particle. $v_{t}$ is the tangential velocity of the particles.

There is a maximum of normal stress $\sigma_{\max }$ and tangential stress $\tau_{\max }$. The bond is broken when the stress exceeds the limit value, such as Eq. (11) and (12).

$$
\sigma_{\max }<\frac{-F_{n}}{A}+\frac{2 T_{t}}{J} R_{B}
$$

$$
\tau_{\max }<\frac{-F_{t}}{A}+\frac{T_{n}}{J} R_{B}
$$

The size of the ore model is mainly determined according to the feeding particle size and the proportion of particle size of the crusher. The particles are filled according to a certain coefficient, and the filling model is shown in Eq. (13) [38].

$$
\alpha V_{\text {Rel }}=N V_{\text {Fraction }}
$$

where, $\alpha$ is the filling volume fraction, and the general value is 0.56. $V_{R e l}$ is the volume of the actual mineral particles. $V_{\text {Fraction }}$ is the volume of small particles. $N$ is the number of small particles required for filling. It can not only ensure the authenticity of simulation, but also improve the efficiency of simulation output when the radius of small particles is 60.00 $\mathrm{mm}$.

\subsubsection{Multiscale particle bonding model}

(1) Definition of multiscale particle bonding model

The mineral multiscale particle model refers to the mineral model constructed by the small particle sphere that obeys a certain distribution or a variety of different distribution when the external shape of the mineral is determined. These simulated minerals have the same characteristics as real minerals in shape, internal structure and mechanical properties.

(2) Mineral multiscale particle bonding model

The construction process of mineral multiscale particle model is shown in Figure 2. Its construction mainly follows several steps (Figure 3).

First, Field data collection. Second, three-dimensional(3D) mineral model was established. Third, the 3D mineral model is imported into DEM to determine the particle size of the filled elementary sphere, and generate and replace the mineral model. Fourth, the coordinate information of filling mineral particles is extracted to establish the file. Fifth, Set the initial value of the parameters of the cohesive particle model. Sixth, the multiscale cohesive particle model is constructed by setting parameters. The large minerals are composed of several small minerals in the process of establishing multi-scale mineral bonding model. Each small mineral is composed of small particles which obey normal distribution. The contact between particles is bonded by the set contact bond, and achieves the internal mechanical characteristics of minerals.

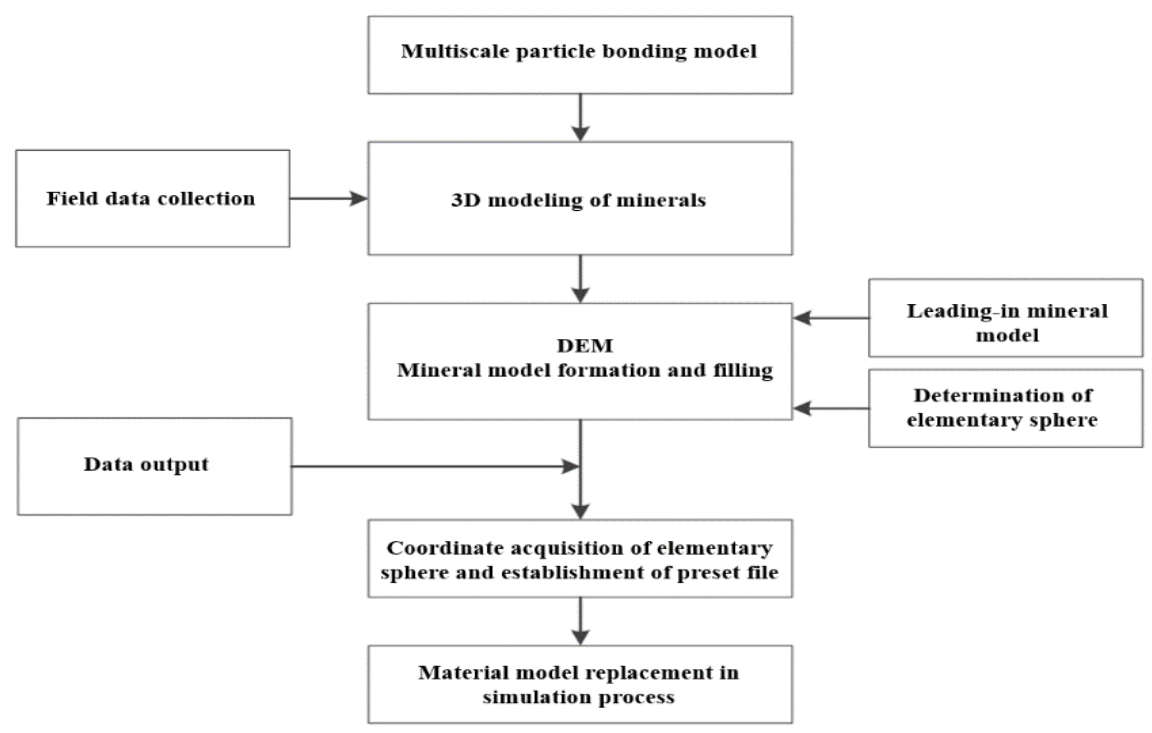

Figure 2. Flow chart of mineral multiscale particle model construction 

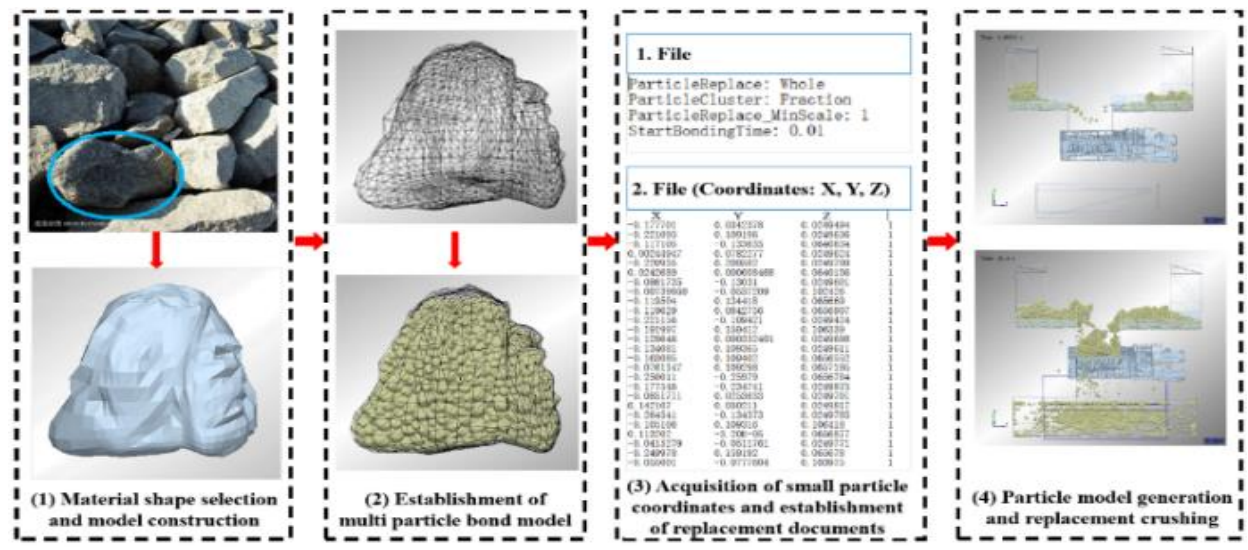

Figure 3. Construction steps of multiscale bonding model

The reasonable setting of contact bond is very important for the real simulation process of mineral crushing. Therefore, the contact force between the filled particles should be calculated accurately. The contact force between minerals can be generally divided into two kinds: tangential stiffness and normal stiffness. The tangential stiffness prevents the tangential movement of small particles, and the normal stiffness prevents the normal deformation of small particles. The relationship between particle contact force and particle displacement can be divided into linear and nonlinear. The nonlinear contact calculation is more stable and practical. According to Hertz contact theory, the relationship between contact force and displacement is shown in Eq. (14) [39].

$$
\left\{\begin{array}{c}
F=\frac{4}{3} E^{*}\left(R^{*}\right)^{\frac{1}{2}} \delta^{\frac{3}{2}} \\
A=\left(\frac{3 F R^{*}}{4 E^{*}}\right)^{\frac{1}{3}}
\end{array}\right.
$$

The simulation process needs to use the same material, so the filled small particles have the same elastic modulus and Poisson's ratio [40]. The normal force $F_{n}$ and normal stiffness $K_{n}$ between small particles, as shown in Eq. (15).

$$
\left\{\begin{array}{c}
F_{n}=\frac{2 E}{3\left(1-\mu^{2}\right)}\left(R^{*}\right)^{\frac{1}{2}} \mu_{n}^{\frac{3}{2}} \\
K_{n}=\frac{2 E}{3\left(1-\mu^{2}\right)}\left(R^{*}\right)^{\frac{1}{2}}
\end{array}\right.
$$

The relationship between normal stiffness and tangential stiffness of mineral particles can be expressed as follows: $K_{s}=\lambda K_{n}$ (The value range of $\lambda$ is $\left.\left(\frac{2}{3}, 1\right)\right) . \lambda$ is related to the stiffness coefficient. In conclusion, the tangential force $F_{s}$ and the tangential stiffness $K_{s}$ of mineral particles are shown in Eq. (16).

$$
\left\{\begin{array}{c}
F_{s}=\lambda K_{n} \mu_{s}^{\frac{3}{2}} \\
K_{s}=\left(\frac{E}{1+\mu}\right)^{\frac{3}{2}} \frac{\left[12(1-\mu) R^{*} F_{n}\right]^{\frac{1}{3}}}{2-\mu}
\end{array}\right.
$$

where, $F$ is the interaction force between particles. $A$ is the displacement between particles. $E^{*}$ is the elastic modulus between adjacent particles. $E$ is the elastic modulus between particles. $R^{*}$ is the contact radius between particles. $\mu_{n}$ and $\mu_{s}$ are the normal and tangential relative displacements of particles, respectively. $\delta$ is the contact deformation. $\mu$ is the Poisson's ratio of the material.

Eq. (14) to (16) were the normal and tangential stiffness obtained from the corresponding physical experiments. The normal stiffness coefficient and tangent stiffness coefficient used in the simulation should be deduced by the discrete element theory. The final formula is Eq. (17).

$$
\left\{\begin{array}{c}
K_{n}=\frac{4}{3}\left(\frac{1-v_{1}^{2}}{E}+\frac{1-v_{2}^{2}}{E}\right)^{-1}\left(\frac{r_{1}+r_{2}}{r_{1} r_{2}}\right)^{-\frac{1}{2}} \\
K_{s}=\left(\frac{1}{2} \sim \frac{2}{3}\right) K_{n}
\end{array}\right.
$$

where, $K_{n}$ is the normal stiffness coefficient of particles. $K_{s}$ is the tangential stiffness coefficient of the particles. $v_{1}$ and $v_{2}$ are the Poisson's ratio of the material. $r_{1}$ and $r_{2}$ are particle radius. The multiscale particle bonding model can analyze the influence of mineral particle size and distribution on energy saving operation of crushing station.

\section{RESULTS AND DISCUSSION}

\subsection{Crusher model and simulation parameters}

\subsubsection{Model establishment of crusher}

Combined with crushing mechanism and mechanical structure parameters of MMD 1000 crusher, as shown in Table 1. The 3D model of crusher established by $3 \mathrm{D}$ modeling software (PROE and SOLIDWORK) is shown in Figure 4 [54].

Table 1. Main parameters of double-geared roller crusher

\begin{tabular}{cc}
\hline Crusher parameters & Describe \\
\hline Arrangement of & 3 teeth, 9 ring gear, 2 \\
crushing teeth & broken shafts \\
Inlet size & $2330 \mathrm{~mm} \times 2960 \mathrm{~mm}$ \\
Crusher depth & $1200 \mathrm{~mm}$ \\
Rotor diameter & $1000 \mathrm{~mm}$ \\
\hline
\end{tabular}

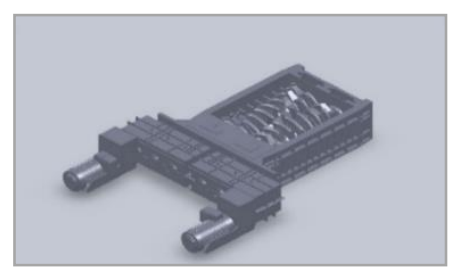

Figure 4. 3D model of double-geared roller crusher 

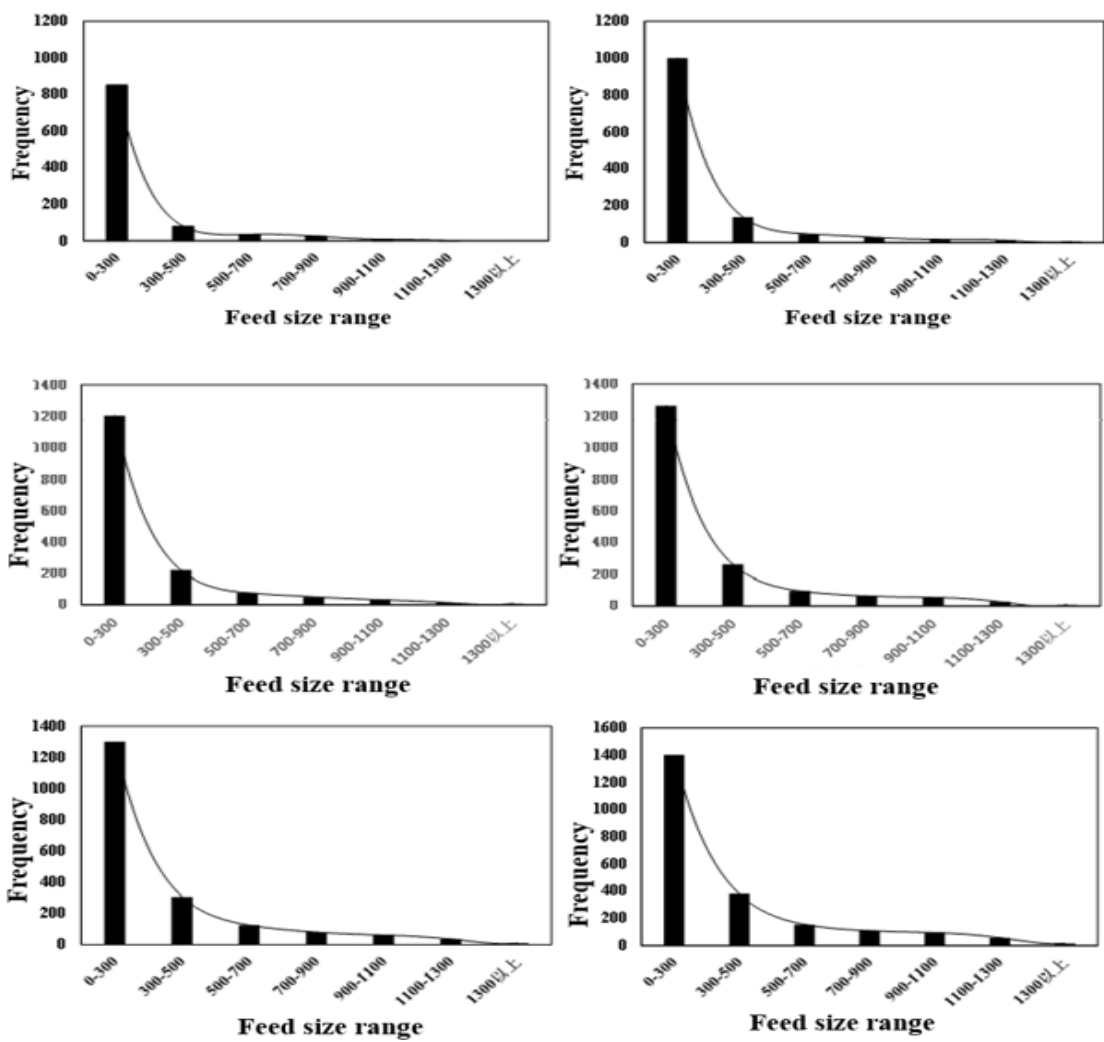

Figure 5. Frequency distribution histogram of feed particle size

Table 2. Statistical data of feed particle size distribution frequency

\begin{tabular}{ccccccc}
\hline Size $(\mathbf{m m})$ & Heidaigou & Houlinhe & Xiyi & Pingshuo & Yimin & Baorixile \\
\hline $0-300$ & 850 & 1000 & 1200 & 1260 & 1300 & 1400 \\
$300-500$ & 80 & 138 & 218 & 261 & 308 & 378 \\
$500-700$ & 35 & 46 & 76 & 96 & 126 & 156 \\
$700-900$ & 25 & 28 & 51 & 64 & 81 & 109 \\
$900-1100$ & 8 & 17 & 32 & 55 & 62 & 95 \\
$1100-1300$ & 2 & 12 & 14 & 27 & 36 & 57 \\
$1300 \leq$ & 0 & 5 & 7 & 9 & 10 & 15 \\
\hline
\end{tabular}

\subsubsection{Simulation parameters}

(1) Mineral size distribution

The particle size distribution is relatively random in the crushing station of open pit mine, and the proportion of each particle grade is different. Based on this, field investigation and sampling were carried out on the particle size distribution of six coal mining enterprises. Feeding characteristics in unit time are classified statistically. The large mineral is set to exceed the size standard of crusher feed. The results showed that bulk ratio of feed particle size distribution is mainly between $15.00 \%$ and $40.00 \%$. The particle size range of $0 \sim 300.00 \mathrm{~mm}$ has the highest frequency. The corresponding frequency histogram of feed particle size distribution is shown in Figure 5 above.

The frequency statistics of feed particle size distribution of six coal mining enterprises is shown in Table 2 above.

In the process of simulation, the product size of crusher is $300.00 \mathrm{~mm}$. The mineral particle size after crushing: $L_{\min } \leq U \leq L_{\max }=300.00 \mathrm{~mm}$. In addition, the crusher is mainly used in the coarse crushing or medium crushing links of the open pit mine. In the actual working condition, only a small amount of over crushed minerals was found in the discharged part of the crushed minerals. Therefore, the size of the elementary ball in the fracture of small-sized particles is smaller than that of the discharge particles randomly. It can meet the requirements of the crusher when the mineral feeding size is less than $2000.00 \mathrm{~mm}$. The mineral particle size generation size is divided into 10 grades in order to reduce the amount of calculation, energy consumption, simulation time and ensure that the particle size is easy to distinguish. That is $250.00 \mathrm{~mm}, 450.00 \mathrm{~mm}, 600.00 \mathrm{~mm}, 800.00 \mathrm{~mm}, 1000.00 \mathrm{~mm}$, $1200.00 \mathrm{~mm}, 1400.00 \mathrm{~mm}, 1600.00 \mathrm{~mm}, 1800.00 \mathrm{~mm}$, $2000.00 \mathrm{~mm}$, and the number of mineral particles in each group is generated randomly.

The feeding frequency in Figure 5 refers to the proportion of each particle size range in the feeding amount of crushing station in unit time. The real-time change range of the particle size distribution of the crusher cannot be accurately determined due to the strong dynamic randomness of the particle size distribution of the crusher. It can be basically determined that the proportion of the bulk of feed particle size is between $15.00 \% \sim 40.00 \%$ according to the statistics of feed particle size distribution data of several open pit coal mines (Table 2). The bulk proportion of feed particle size is set between $15.00 \% \sim 40.00 \%$ in the simulation in order to make the crusher to adapt to the influence of different feed particle size distribution. They were divided into 6 groups: $15.00 \%$ in group A, $20.00 \%$ in group B, $25.00 \%$ in group C, $30.00 \%$ in group $\mathrm{D}, 35.00 \%$ in Group $\mathrm{E}$ and $40.00 \%$ in group $\mathrm{F}$. 
(2) Material parameter setting

The broken object of simulation is mineral, which comes from Heidaigou open pit mine. The main parameters are shown in Table 3 [41].

Table 3. Material parameters

\begin{tabular}{cc}
\hline Parameters & Numerical value \\
\hline Density & $1540 \mathrm{~kg} / \mathrm{m}^{3}$ \\
Compressive strength & $1.5 \mathrm{e}+7 \mathrm{MPa}$ \\
Restitution coefficient & 0.20 \\
Poisson's ratio & 0.36 \\
Shear modulus & $4.6 \mathrm{e}+08 \mathrm{~Pa}$ \\
Elastic modulus & $1 \mathrm{e}+09 \mathrm{~Pa}$ \\
Static friction coefficient & 0.50 \\
Rolling friction coefficient & 0.01 \\
Normal stiffness & $3 \mathrm{e}+07 \mathrm{~N} / \mathrm{m}^{3}$ \\
Tangential stiffness & $5 \mathrm{e}+06 \mathrm{~N} / \mathrm{m}^{3}$ \\
Normal shear modulus & $2 \mathrm{e}+06 \mathrm{~Pa}$ \\
Tangential shear modulus & $2 \mathrm{e}+05 \mathrm{~Pa}$ \\
\hline
\end{tabular}

The contact parameters between different materials were optimized by DEM in order to eliminate unnecessary stress and strain in simulation as soon as possible. Smaller recovery coefficient and static friction coefficient are used in the setting of material properties. The material contact parameters are shown in Table 4.

Table 4. Material contact parameters

\begin{tabular}{ccc}
\hline Material contact parameters & Coal & Ore \\
\hline Restitution coefficient & 0.20 & 0.20 \\
Static friction coefficient & 0.50 & 0.50 \\
Rolling friction coefficient & 0.01 & 0.01 \\
\hline
\end{tabular}

(3) Equipment parameter setting

The mechanical motion parameters mainly include the speed of the crusher tooth roller and the feeding speed of the feeder in the simulation process of mineral crushing. The tooth roll speed $(\mathrm{r} / \mathrm{min})$ is determined by the ratio of motor speed and transmission of reducer according to the mechanical parameters of MMD 1000 crusher. That is to say, the motor speed of the crusher is $1485 \mathrm{r} / \mathrm{min}$, the transmission ratio of reducer is $45: 1$, and the calculated standard tooth roller speed is $33.00 \mathrm{r} / \mathrm{min}$. The tooth roll speed can be adjusted properly by frequency converter in order to adapt to different feeding conditions, and the range of adjustment is $\pm 5.00 \% \sim \pm 11.00 \%$ of the standard speed. The adjustment of the tooth roller speed of the crusher should be divided into five levels according to the experience of experts on site. Therefore, the tooth roller speed selected in the simulation is $29.60 \mathrm{r} / \mathrm{min}, 31.30 \mathrm{r} / \mathrm{min}$, $33.00 \mathrm{r} / \mathrm{min}, 34.70 \mathrm{r} / \mathrm{min}$ and $36.40 \mathrm{r} / \mathrm{min}$ respectively. The parameter setting of tooth roll speed is shown in Figure 6 . The feeding speed of the plate feeder could be adjusted by frequency according to the investigation and evidence collection of $5 \#$ crushing station in Heidaigou open pit mine. The regulating range is $0 \sim 0.60 \mathrm{~m} / \mathrm{s}$, the corresponding frequency is $0 \sim 50.00 \mathrm{~Hz}$, the adjustment degree is $0.10 \mathrm{~m} / \mathrm{s}$, and the feeding speed is set as shown in Figure 7. The height of material level in crusher cavity can be adjusted in $[0,1.50$ $\mathrm{m}$ ] range according to the load state of crusher working condition. It can be divided into five grades: no load 0 , low load $(0,0.20 \mathrm{~m}]$, normal $(0.20 \mathrm{~m}, 1.00 \mathrm{~m})$, heavy load $(1.00 \mathrm{~m}$, $1.50 \mathrm{~m}$ ] and overload $(1.50 \mathrm{~m},+\infty)$.

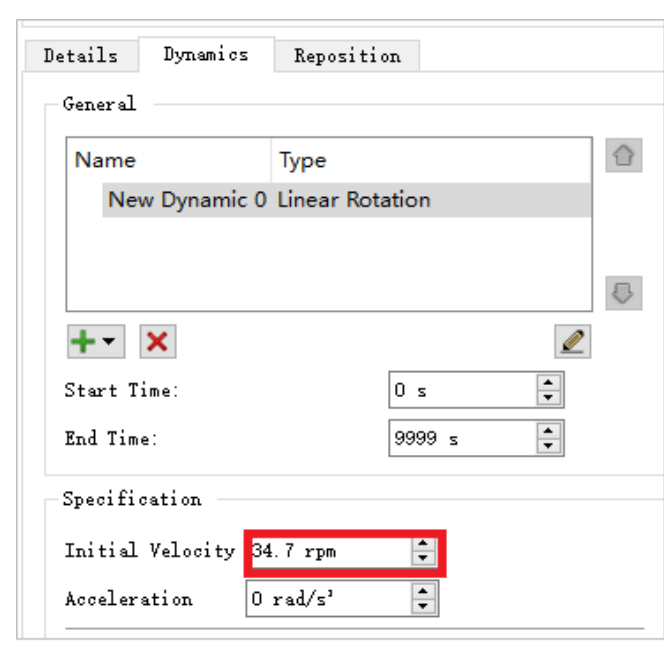

Figure 6. Gear speed setting

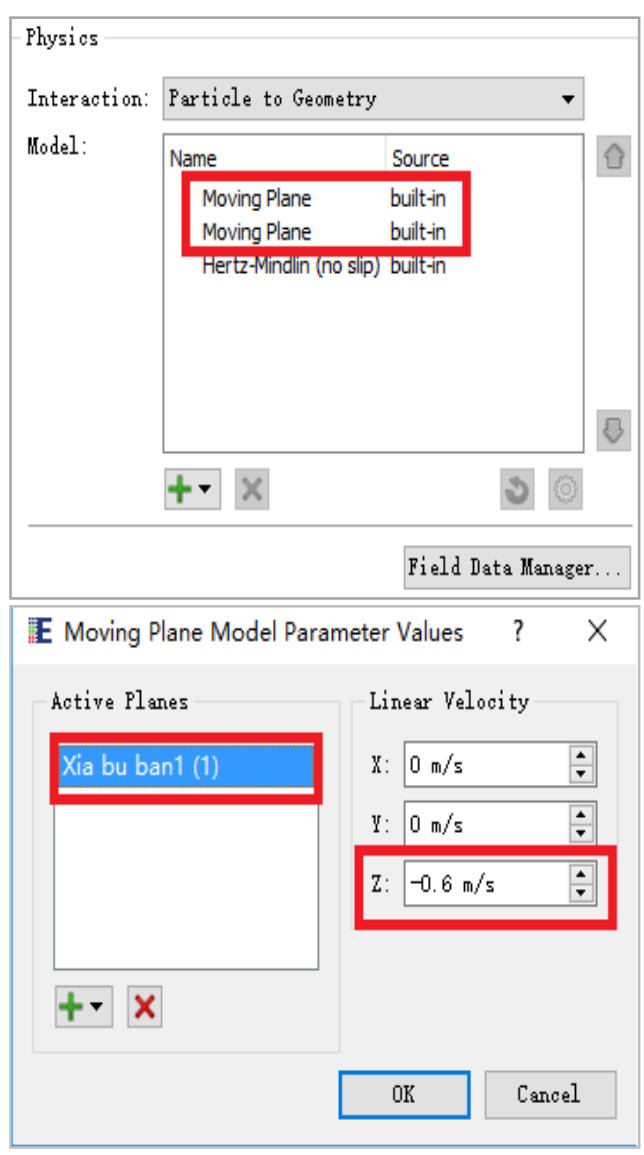

Figure 7. Feed speed setting

(4) Simulation time

The key step of using DEM simulation is to set a reasonable time step. The time step is the theoretical maximum value of quasi-static particles in DEM simulation, which is determined by Eq. (18) [42]. Time step is the time difference between every two operations in the simulation calculation module, in order to ensure the continuity of simulation [43]. The initial time step is set as $5 \% \sim 40 \%$ of the Reyleigh time step according to the simulation experience [44].

$$
T_{R}=\pi R\left(\frac{\rho}{G}\right)^{\frac{1}{2}}(0.161 \sigma+0.877)^{-1}
$$


where, $T_{R}$ is the Rayleigh time step. $R$ is the particle radius. $\rho$ is material density. $G$ is the modulus of elasticity. $\sigma$ is Poisson's ratio.

The simulation time step is $1.65 \times 10^{-6} \mathrm{~s}$ according to Eq. (18). The fixed time step was $18.37 \%$ of the Reyleigh time step. The purpose of simulation is to reflect the influence of various parameters on crushing energy consumption. The simulation time should be as short as possible on the premise of ensuring the simulation authenticity. It is reasonable to set the simulation time to $120.00 \mathrm{~s}$.

To calculate the contact force between particles, the common method is to divide the whole calculation area into several square grids, which is called meshing [45]. The relationship between the defined side length $l_{b o x}$ and the maximum particle diameter $d_{b o x}: d_{b o x}<l_{b o x}<2 d_{b o x}$. The mesh size is divided into two times of the primitive ball particles according to the characteristics of DEM setting, as shown in Figure 8 .

Simulator Grid
Smallest Radius ( $\mathrm{R} \mathrm{min}$ ):

Figure 8. Meshing

The files Particle Cluster Data. txt and Particle_Replacement prefs after parameter setting. txt in DEM need to be loaded to complete mineral generation and replacement, as shown in Figure 9.

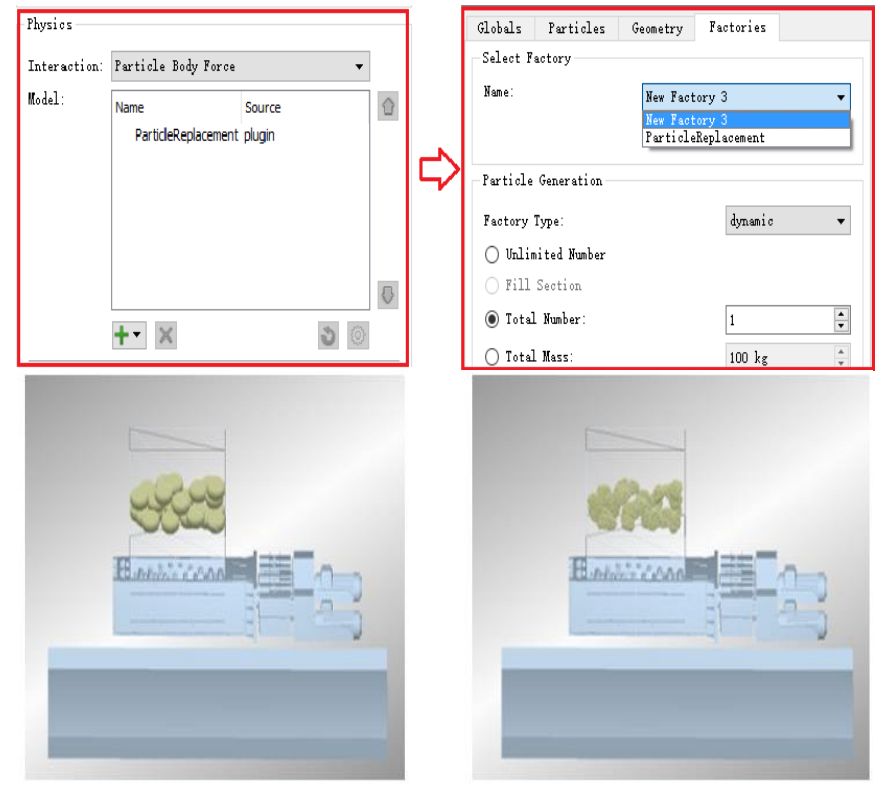

Figure 9. Material generation and replacement

(4) fracture number of mineral bonding and the fracture time Hertz-Mindlin bonding contact model is used to simulate the formation of minerals.

Bonding can be regarded as the bonding in the model. Therefore, the relationship among the distribution of mineral block, the rotation speed of tooth roller and the feeding speed can be obtained by analyzing the relationship between the fracture number of mineral bonding and the fracture time (as shown in Figure 10).

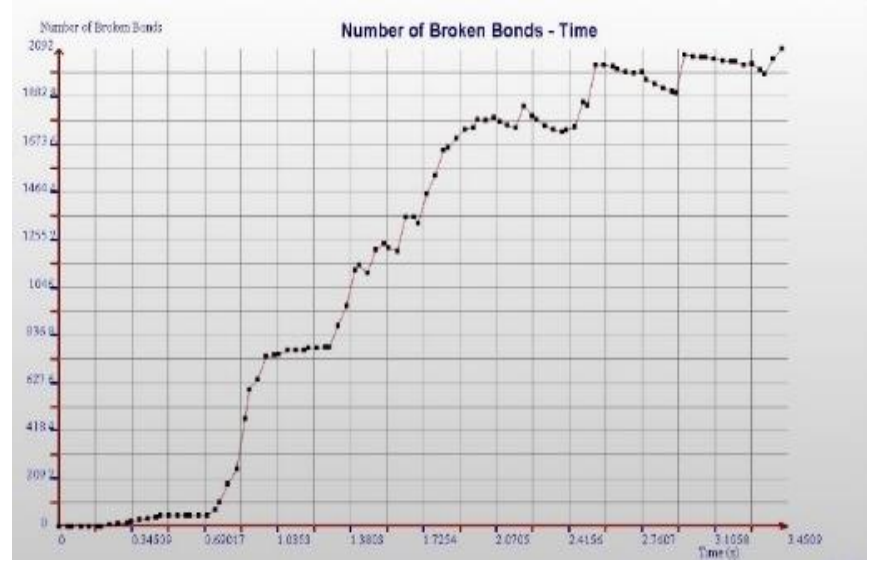

Figure 10. The relationship between the number of bonding fractures and the crushing time

\subsection{Establishment process of multiparameter coupling coordinated speed regulation crushing strategy}

\subsubsection{Speed regulation analysis based on simulation}

The results can be obtained by analyzing the sequence of the number of bond breaks from Figure 11 to Figure 16. The number of bonding fracture per unit time increases gradually with the acceleration of the speed of the tooth roller and the feeding speed, that is, the crushing efficiency and energy saving effect of crusher are gradually improved. The following rules can be obtained by comparing and analyzing the simulation results of different proportion of feed particle size distribution.

(1) The tooth roll speed and the feeding speed are adjusted when the proportion of the large mineral size increases from $15.00 \% \sim 20.00 \%$ to more than $20.00 \%$, the crushing efficiency does not change significantly. The reason is that the bite efficiency of the crushing teeth decreases with the increase of the proportion of large blocks, and the minerals in the crushing cavity pile up continuously with the continuous feeding of minerals, reducing the crushing efficiency. According to the simulation results of group $\mathrm{D}, \mathrm{E}$ and $\mathrm{F}$, the feeding speed increased from $0.20 \mathrm{~m} / \mathrm{s}$ to $0.40 \mathrm{~m} / \mathrm{s}$ when the proportion of mineral blocks was higher than $15.00 \%$, the number of bonding fractures increased in unit time, and crushing efficiency and energy saving are improved. The feeding speed increased from $0.40 \mathrm{~m} / \mathrm{s}$ to $0.60 \mathrm{~m} / \mathrm{s}$, the number of bonding fractures decreased in unit time and the crushing efficiency decreased. Therefore, it is not difficult to judge that the feeding speed should not exceed $0.40 \mathrm{~m} / \mathrm{s}$ with the increase of the proportion of large blocks. The maximum speed of the tooth roll should be $36.40 \mathrm{r} / \mathrm{min}$. The number of bonding breaks is the most in the corresponding unit time, and the material passing efficiency and energy saving are the best.

(2) According to the simulation results of group A, B and C, the efficiency of crusher can be increased to a certain extent by adjusting the speed of tooth roll when the proportion of mineral blocks $\leq 15.00 \%$ and the feeding speed was $0.20 \mathrm{~m} / \mathrm{s}$, but the effect was not obvious. The feeding speed increases from $0.20 \mathrm{~m} / \mathrm{s}$ to $0.40 \mathrm{~m} / \mathrm{s}$ when the proportion of large minerals is less than $10.00 \%$, and the number of bond fracture increases obviously. The increasing rate of the number of bonding breaks slows down when the feeding speed increases from $0.40 \mathrm{~m} / \mathrm{s}$ to $0.60 \mathrm{~m} / \mathrm{s}$. It can be judged that the proportion of large mineral block is $<10.00 \%$, the feeding speed was the main factor affecting the crushing efficiency in a certain range, 
and the speed of tooth roll was the secondary factor. Minerals can directly and effectively slide from the crushing chamber to the gap between the roll teeth, roll teeth and side sparse teeth when the proportion of large minerals is relatively low. The screening of crusher is better. The crushing efficiency will be limited if the feeding speed is slow. Therefore, it is suggested that in the process of mineral crushing, when the proportion of large minerals is less than $15 \%$, faster feeding speed and appropriate tooth roller speed should be adopted to improve the crushing efficiency and energy saving effect.

(3) It can be seen from several sets of simulation experiments that the speed of tooth roller and feeding speed affect the crushing process of minerals, but the number of bonding fracture after crushing of minerals with the same feeding particle size distribution in some experiments was significantly different. The main reason is that the large minerals will burst and break in an instant due to the torque and shear of the roller teeth. This kind of bursting causes a sharp increase in the number of bonding breaks at a certain time. In addition, number of bond breaks fluctuates sharply due to the degree of mutual extrusion of some large minerals in the fracture process. The phenomenon will make the broken teeth stressed seriously and easy to wear or break. Therefore, it is recommended to use suitable low tooth roller speed and feed speed matching operation when the large proportion of feed particle size is high.

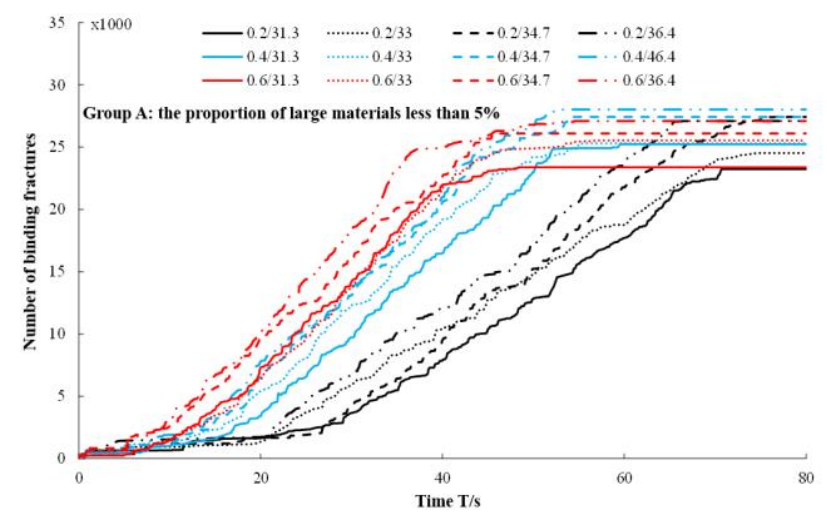

Figure 11. Time sequence diagram of the bonding fractures number

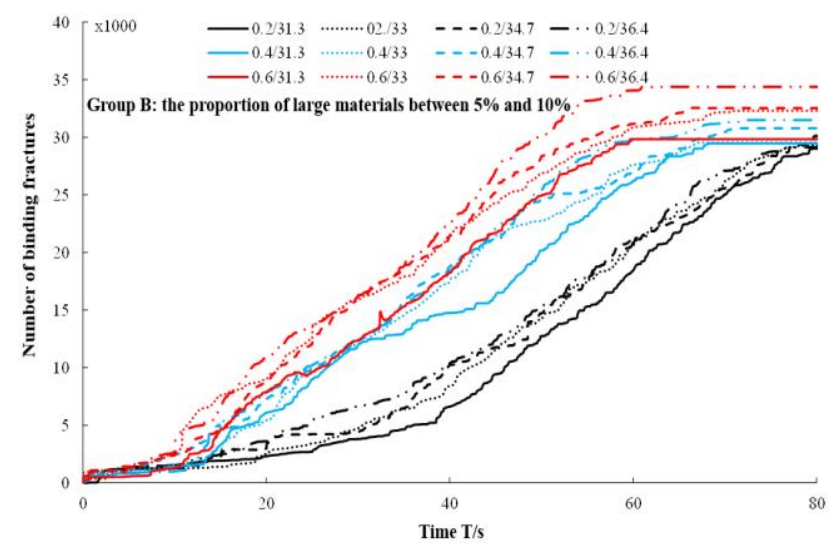

Figure 12. Time sequence diagram of the bonding fractures number
Table 5. Crushing data based on group A (proportion of large materials less than $5 \%$ )

\begin{tabular}{ccccc}
\hline $\begin{array}{c}\text { Feeding } \\
\text { speed } \\
(\mathbf{m} / \mathbf{s})\end{array}$ & $\begin{array}{c}\text { Roller } \\
\text { speed } \\
(\mathbf{r} / \mathbf{m i n})\end{array}$ & $\begin{array}{c}\text { Group A feed size distribution } \\
\text { Material } \\
\text { level } \\
\text { height (m) }\end{array}$ & $\begin{array}{c}\text { Crushing } \\
\text { efficiency } \\
\text { (t/h) }\end{array}$ & $\begin{array}{c}\text { Passing } \\
\text { rate (\%) }\end{array}$ \\
\hline \multirow{5}{*}{0.1} & 31.3 & 0.23 & 1093 & 1.1 \\
& 33 & 0.26 & 1104 & 1.5 \\
& 34.7 & 0.24 & 1107 & 1.6 \\
& 36.4 & 0.27 & 1112 & 1.8 \\
0.2 & 31.3 & 0.33 & 1682 & 2.1 \\
& 33 & 0.34 & 1686 & 2.5 \\
& 34.7 & 0.36 & 1691 & 2.8 \\
& 36.4 & 0.35 & 1687 & 2.7 \\
0.3 & 31.3 & 0.41 & 2563 & 2.8 \\
& 33 & 0.48 & 2552 & 3.1 \\
& 34.7 & 0.42 & 2546 & 3 \\
& 36.4 & 0.47 & 2350 & 3.3 \\
0.4 & 31.3 & 0.52 & 3367 & 3.6 \\
& 33 & 0.54 & 3373 & 3.5 \\
& 34.7 & 0.51 & 3387 & 3.7 \\
& 36.4 & 0.53 & 3350 & 3.4 \\
0.5 & 31.3 & 0.59 & 3423 & 3.9 \\
& 33 & 0.61 & 3411 & 3.8 \\
& 34.7 & 0.58 & 3427 & 3.8 \\
& 36.4 & 0.59 & 3423 & 3.9 \\
0.6 & 31.3 & 0.65 & 3224 & 4.3 \\
& 33 & 0.64 & 3229 & 4.2 \\
& 34.7 & 0.67 & 3191 & 4 \\
& 36.4 & 0.66 & 3212 & 4 \\
\hline
\end{tabular}

Table 6. Crushing data based on group B (proportion of large materials between $5 \%$ and $10 \%$ )

\begin{tabular}{ccccc}
\hline $\begin{array}{c}\text { Feeding } \\
\text { speed } \\
\text { (m/s) }\end{array}$ & $\begin{array}{c}\text { Roller } \\
\text { speed } \\
\text { (r/min) }\end{array}$ & $\begin{array}{c}\text { Group B feed size distribution } \\
\text { Material } \\
\text { level } \\
\text { height }(\mathbf{m})\end{array}$ & $\begin{array}{c}\text { Crushing } \\
\text { efficiency } \\
\text { (t/h) }\end{array}$ & $\begin{array}{c}\text { Passing } \\
\text { rate } \mathbf{( \% )}\end{array}$ \\
\hline \multirow{4}{*}{0.1} & 31.3 & 0.28 & 1017 & 1.3 \\
& 33 & 0.25 & 974 & 1.6 \\
& 34.7 & 0.27 & 982 & 1.5 \\
& 36.4 & 0.33 & 986 & 1.9 \\
0.2 & 31.3 & 0.38 & 1533 & 2.4 \\
& 33 & 0.37 & 1529 & 2.3 \\
& 34.7 & 0.39 & 1541 & 2.5 \\
& 36.4 & 0.39 & 1537 & 2.4 \\
0.3 & 31.3 & 0.56 & 2369 & 3.5 \\
& 33 & 0.53 & 2371 & 3.4 \\
& 34.7 & 0.55 & 2387 & 3.4 \\
& 36.4 & 0.53 & 2360 & 3.5 \\
0.4 & 31.3 & 0.63 & 3113 & 3.9 \\
& 33 & 0.65 & 3132 & 3.8 \\
& 34.7 & 0.63 & 3129 & 3.9 \\
& 36.4 & 0.65 & 3126 & 4 \\
0.5 & 31.3 & 0.74 & 3156 & 4.1 \\
& 33 & 0.74 & 3187 & 4.2 \\
& 34.7 & 0.76 & 3193 & 4.3 \\
& 36.4 & 0.74 & 3167 & 4.2 \\
& 31.3 & 0.8 & 2824 & 4.8 \\
& 33 & 0.78 & 2819 & 4.6 \\
& 34.7 & 0.77 & 2797 & 4.7 \\
& 36.4 & 0.79 & 2813 & 4.7 \\
\hline
\end{tabular}


Table 7. Crushing data based on group $\mathrm{C}$ (proportion of large materials between $10 \%$ and $15 \%$ )

\begin{tabular}{ccccc}
\hline $\begin{array}{l}\text { Feeding } \\
\text { speed } \\
(\mathbf{m} / \mathbf{s})\end{array}$ & $\begin{array}{c}\text { Roller } \\
\text { speed } \\
\text { (r/min) }\end{array}$ & $\begin{array}{c}\text { Group C feed size distribution } \\
\text { Material } \\
\text { level height } \\
\text { (m) }\end{array}$ & $\begin{array}{c}\text { Crushing } \\
\text { efficiency } \\
\text { (t/h) }\end{array}$ & $\begin{array}{c}\text { Passing } \\
\text { rate } \\
(\mathbf{\%})\end{array}$ \\
\hline & 31.3 & 0.27 & 957 & 2 \\
0.1 & 33 & 0.32 & 961 & 1.9 \\
& 34.7 & 0.31 & 953 & 2.5 \\
& 36.4 & 0.29 & 946 & 2.3 \\
& 31.3 & 0.42 & 1353 & 3.2 \\
0.2 & 33 & 0.41 & 1342 & 3.5 \\
& 34.7 & 0.43 & 1401 & 3.4 \\
& 36.4 & 0.45 & 1348 & 3.4 \\
& 31.3 & 0.59 & 2129 & 3.8 \\
0.3 & 33 & 0.61 & 2131 & 4 \\
& 34.7 & 0.58 & 2143 & 3.8 \\
& 36.4 & 0.59 & 2150 & 3.9 \\
& 31.3 & 0.68 & 2476 & 4.4 \\
0.4 & 33 & 0.7 & 2483 & 4.5 \\
& 34.7 & 0.67 & 2491 & 4.4 \\
& 36.4 & 0.68 & 2497 & 4.3 \\
& 31.3 & 0.76 & 2533 & 4.9 \\
0.5 & 33 & 0.77 & 2542 & 4.8 \\
& 34.7 & 0.79 & 2539 & 5.1 \\
& 36.4 & 0.75 & 2536 & 5 \\
& 31.3 & 0.89 & 2524 & 5.3 \\
0.6 & 33 & 0.88 & 2519 & 5.2 \\
& 34.7 & 0.86 & 2517 & 5.5 \\
& 36.4 & 0.87 & 2513 & 5.3 \\
\hline
\end{tabular}

Table 8. Crushing data based on group D (proportion of large materials between $15 \%$ and $20 \%$ )

\begin{tabular}{ccccc}
\hline $\begin{array}{c}\text { Feeding } \\
\text { speed } \\
(\mathbf{m} / \mathbf{s})\end{array}$ & $\begin{array}{c}\text { Roller } \\
\text { speed } \\
\text { (r/min) }\end{array}$ & $\begin{array}{c}\text { Group D feed size distribution } \\
\text { Material } \\
\text { level } \\
\text { height }(\mathbf{m})\end{array}$ & $\begin{array}{c}\text { Crushing } \\
\text { efficiency } \\
\text { (t/h) }\end{array}$ & $\begin{array}{c}\text { Passing } \\
\text { rate } \mathbf{( \% )}\end{array}$ \\
\hline \multirow{4}{*}{0.1} & 31.3 & 0.33 & 832 & 2.8 \\
& 33 & 0.32 & 874 & 2.8 \\
& 34.7 & 0.34 & 917 & 2.9 \\
& 36.4 & 0.32 & 930 & 2.8 \\
0.2 & 31.3 & 0.47 & 1257 & 3.9 \\
& 33 & 0.45 & 1281 & 4 \\
& 34.7 & 0.48 & 1283 & 3.8 \\
& 36.4 & 0.44 & 1277 & 3.9 \\
0.3 & 31.3 & 0.65 & 1962 & 4.3 \\
& 33 & 0.66 & 1973 & 4.4 \\
& 34.7 & 0.63 & 1984 & 4.2 \\
& 36.4 & 0.67 & 1960 & 4.2 \\
0.4 & 31.3 & 0.74 & 2226 & 5.3 \\
& 33 & 0.69 & 2223 & 5.6 \\
& 34.7 & 0.71 & 2232 & 5.4 \\
& 36.4 & 0.73 & 2210 & 5.7 \\
0.5 & 31.3 & 0.86 & 2274 & 5.9 \\
& 33 & 0.94 & 2269 & 6.2 \\
& 34.7 & 0.89 & 2283 & 6.1 \\
& 36.4 & 0.93 & 2277 & 6.2 \\
& 31.3 & 0.94 & 2219 & 6.6 \\
& 33 & 0.97 & 2207 & 6.8 \\
& 34.7 & 0.96 & 2197 & 6.8 \\
& 36.4 & 0.97 & 2223 & 6.7 \\
\hline
\end{tabular}

Table 9. Crushing data based on group E (proportion of large materials between $20 \%$ and $25 \%$ )

\begin{tabular}{ccccc}
\hline $\begin{array}{c}\text { Feeding } \\
\text { speed } \\
\text { (m/s) }\end{array}$ & $\begin{array}{c}\text { Roller } \\
\text { speed } \\
\text { (r/min) }\end{array}$ & $\begin{array}{c}\text { Group E feed size distribution } \\
\text { Material } \\
\text { level } \\
\text { height (m) }\end{array}$ & $\begin{array}{c}\text { Crushing } \\
\text { efficiency } \\
\text { (t/h) }\end{array}$ & $\begin{array}{c}\text { Passing } \\
\text { rate } \mathbf{( \% )}\end{array}$ \\
\hline \multirow{5}{*}{0.1} & 31.3 & 0.34 & 772 & 2.9 \\
& 33 & 0.36 & 763 & 3 \\
& 34.7 & 0.36 & 787 & 3.2 \\
& 36.4 & 0.38 & 806 & 3.1 \\
0.2 & 31.3 & 0.51 & 1033 & 4.4 \\
& 33 & 0.49 & 1024 & 4.7 \\
& 34.7 & 0.53 & 1031 & 4.3 \\
& 36.4 & 0.52 & 1047 & 4.4 \\
0.3 & 31.3 & 0.69 & 1532 & 5.3 \\
& 33 & 0.7 & 1556 & 5.4 \\
& 34.7 & 0.66 & 1544 & 5.4 \\
& 36.4 & 0.65 & 1521 & 5.5 \\
0.4 & 31.3 & 0.77 & 1922 & 6.3 \\
& 33 & 0.79 & 1937 & 6.1 \\
& 34.7 & 0.75 & 1915 & 6.4 \\
& 36.4 & 0.73 & 1937 & 6.2 \\
0.5 & 31.3 & 0.89 & 1887 & 6.5 \\
& 33 & 1.01 & 1879 & 6.6 \\
& 34.7 & 0.95 & 1876 & 6.5 \\
& 36.4 & 0.97 & 1877 & 6.5 \\
0.6 & 31.3 & 0.98 & 1811 & 6.9 \\
& 33 & 1.03 & 1823 & 7.3 \\
& 34.7 & 1 & 1825 & 7.1 \\
& 36.4 & 0.95 & 1823 & 7.1 \\
\hline
\end{tabular}

Table 10. Crushing data based on group F (proportion of large materials more than $25 \%$ )

\begin{tabular}{|c|c|c|c|c|}
\hline \multirow[b]{2}{*}{$\begin{array}{c}\text { Feeding } \\
\text { speed } \\
(\mathrm{m} / \mathrm{s})\end{array}$} & \multirow[b]{2}{*}{$\begin{array}{c}\text { Roller } \\
\text { speed } \\
\text { (r/min) }\end{array}$} & \multicolumn{3}{|c|}{ Group $F$ feed size distribution } \\
\hline & & $\begin{array}{c}\text { Material } \\
\text { level } \\
\text { height } \\
(\mathbf{m})\end{array}$ & $\begin{array}{l}\text { Crushing } \\
\text { efficiency } \\
(t / h)\end{array}$ & $\begin{array}{l}\text { Passing } \\
\text { rate (\%) }\end{array}$ \\
\hline \multirow{4}{*}{0.1} & 31.3 & 0.42 & 530 & 4.2 \\
\hline & 33 & 0.45 & 536 & 4.2 \\
\hline & 34.7 & 0.44 & 541 & 4.1 \\
\hline & 36.4 & 0.48 & 532 & 4.2 \\
\hline \multirow{5}{*}{0.2} & 31.3 & 0.55 & 882 & 5.5 \\
\hline & 33 & 0.58 & 877 & 5.4 \\
\hline & 34.7 & 0.57 & 883 & 5.4 \\
\hline & 36.4 & 0.56 & 889 & 5.7 \\
\hline & 31.3 & 0.67 & 1169 & 6.1 \\
\hline \multirow{2}{*}{0.3} & 33 & 0.7 & 1174 & 6.1 \\
\hline & 34.7 & 0.69 & 1166 & 5.9 \\
\hline \multirow{5}{*}{0.4} & 36.4 & 0.72 & 1126 & 6.2 \\
\hline & 31.3 & 0.81 & 1594 & 6.4 \\
\hline & 33 & 0.82 & 1539 & 6.5 \\
\hline & 34.7 & 0.79 & 1527 & 6.6 \\
\hline & 36.4 & 0.81 & 1513 & 6.5 \\
\hline \multirow{4}{*}{0.5} & 31.3 & 0.98 & 1495 & 6.8 \\
\hline & 33 & 1.07 & 1516 & 6.8 \\
\hline & 34.7 & 0.99 & 1503 & 6.7 \\
\hline & 36.4 & 1.02 & 1483 & 6.7 \\
\hline \multirow{4}{*}{0.6} & 31.3 & 1.21 & 1440 & 7.1 \\
\hline & 33 & 1.16 & 1436 & 7.3 \\
\hline & 34.7 & 1.22 & 1501 & 7.3 \\
\hline & 36.4 & 1.15 & 1452 & 7.2 \\
\hline
\end{tabular}




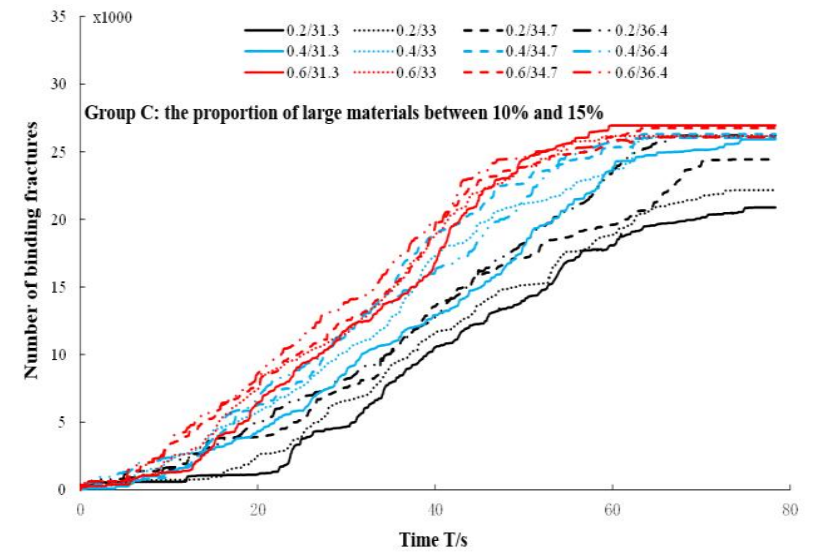

Figure 13. Time sequence diagram of the bonding fractures number

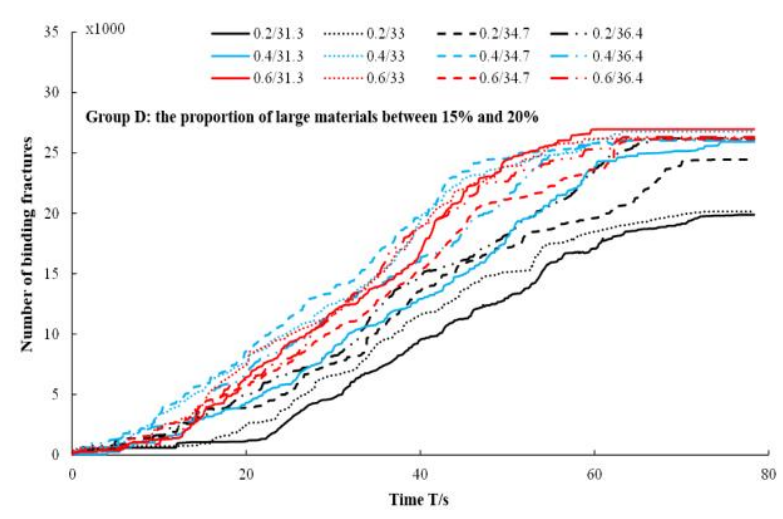

Figure 14. Time sequence diagram of the bonding fractures number

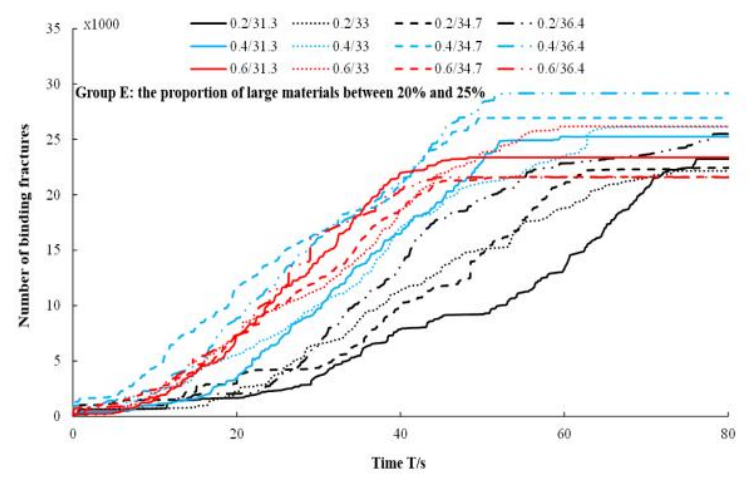

Figure 15. Time sequence diagram of the bonding fractures number

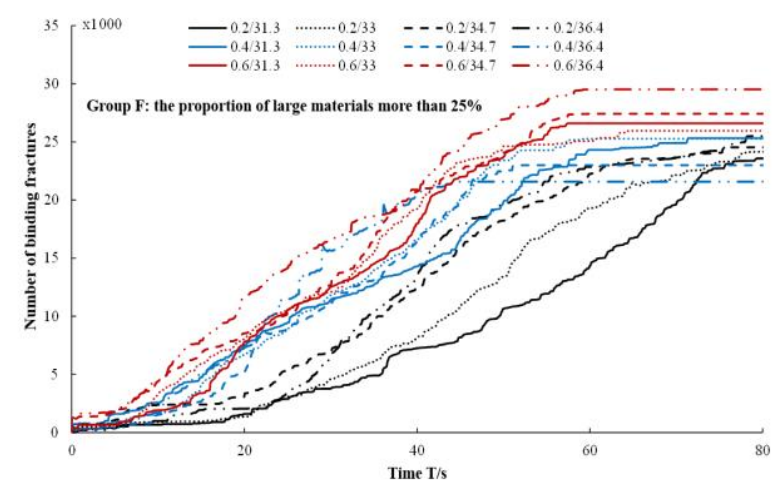

Figure 16. Time sequence diagram of the bonding fractures number
3.2.2 Multiparameter coupling coordinated speed regulation strategy

Feed quantity $Q_{\text {feed }}$ of the plate feeder directly determines crushing quantity $Q_{\text {crush }}$ of the crusher [46]. The change of the feeding characteristics caused "no load, low load, rated load, heavy load, overload" in the running state of the crusher. Therefore, the relationship between $Q_{\text {feed }}$ and $Q_{\text {crush }}$ was analyzed. The strategy of multivariable corresponding parameters coordinated speed regulation was proposed. It provides an effective theoretical basis for the efficient and energy saving operation of crushing station.

$$
\begin{gathered}
Q_{\text {crush }}=Q_{\text {crush }}{ }^{*} D_{i} \theta_{i} \\
Q_{\text {crush }}=\int_{0}^{t}\left(v_{l} K_{l} S_{1}+2 \pi r \frac{\omega}{\varphi} S_{2}+\frac{\omega}{\varphi} V_{\text {volume }}\right) \rho \varepsilon D_{i} \theta_{i} d t
\end{gathered}
$$

where, $Q_{\text {feed }}$ is feed quantity. $Q_{\text {crush }}$ is crushing quantity. $D_{i}$ is the particle size distribution and proportion coefficient of feed per unit time. $\theta_{i}$ is the influence coefficient of material level height of the crushing chamber on its crushing performance. The relationship between $Q_{\text {feed }}$ and $Q_{\text {crush }}$ can be obtained according to the simulation data of Eq. (19), Eq. (20) and Tables 5 10. There are continuous and discontinuous mineral states between $Q_{\text {feed }}$ and $Q_{\text {crush }}$.

(1) Continuous state of minerals

1) When $Q_{\text {feed }}>Q_{\text {crush }}$, the relationship is:

$$
\int_{0}^{t}\left[\frac{S v \rho}{k_{i}}-\left(v_{l} K_{l} S_{l}+2 \pi r \frac{\omega}{\varphi} S_{2}+\frac{\omega}{\varphi} V_{\text {volume }}\right) \rho \varepsilon D_{i} \theta_{i}\right] d t>0
$$

Assuming that the initial feeding speed $v=v_{\max }=0.60 \mathrm{~m} / \mathrm{s}$, according to the simulation results of Eq. (21) and Table 5 Table 10, when the proportion of feeding particle size to the bulk is less than $10.00 \%$, adjusting the tooth roll speed has little effect on the crushing efficiency. It is suggested to reduce the feeding speed $(0.40 \sim 0.50 \mathrm{~m} / \mathrm{s})$, tooth roll speed $R$ is 33.00 $\mathrm{r} / \mathrm{min}$, the height of the material level is basically controlled at $0.50 \sim 0.80 \mathrm{~m}$, and the crushing is the best. It can effectively prevent the jamming fault and ensure the efficient crushing of the crusher when the bulk material accounts for $10.00 \% \sim 20.00 \%$, the feeding speed is $0.40 \mathrm{~m} / \mathrm{s}$, the gear roller speed $R$ is $33.00 \mathrm{r} / \mathrm{min} \sim 34.70 \mathrm{r} / \mathrm{min}$, and height of the material level is $0.50 \mathrm{~m} \sim 0.90 \mathrm{~m}$. The height of the material level will rise continuously (the height of the material level is $1.00 \sim 1.50$ $\mathrm{m}$ ) when the proportion of feeding particle size is more than $20.00 \%$. The feeding speed should be set as $0.20 \sim 0.40 \mathrm{~m} / \mathrm{s}$, and the tooth roll speed should be set as $34.70 \sim 36.40 \mathrm{r} / \mathrm{min}$ in order to reduce the rate of mineral powder passing, improve the efficiency of crushing and screening, and avoid blocking failure of crusher. The feeding speed of the plate feeder shall be reduced again, or even the feeding shall be stopped if the material level height is still high after the speed regulation. It is assumed that the initial feeding speed $v<v_{\max }=0.60 \mathrm{~m} / \mathrm{s}$. When the proportion of mineral blocks is less than $10.00 \%$ and the tooth roller speed is adjustable, if the material level height is increasing, the tooth roller speed can be increased properly. The feeding speed shall be reduced immediately if the height of the material level cannot be reduced.

2) When $Q_{\text {feed }}=Q_{\text {crush }}$, the relationship is:

$$
\int_{0}^{t}\left[\frac{S v \rho}{k_{i}}-\left(v_{l} K_{l} S_{1}+2 \pi r \frac{\omega}{\varphi} S+\frac{\omega}{\varphi} V_{\text {volume }}\right) \rho \varepsilon D_{i} \theta_{i}\right] d t \cong 0
$$


It is assumed that the initial feeding speed $v=v_{\max }=0.60 \mathrm{~m} / \mathrm{s}$. According to the simulation results of Eq. (22) and Table 5 Table 10, when the proportion of large pieces of material size is more than $20.00 \%$, the feeding speed should be set at 0.20 $\mathrm{m} / \mathrm{s} \sim 0.40 \mathrm{~m} / \mathrm{s}$, the tooth roll speed should be set at $33.00 \mathrm{r} / \mathrm{min}$, and the material level height should be controlled at $0.50 \mathrm{~m} \sim$ $0.80 \mathrm{~m}$, which can avoid the blocking of material in the machine cavity. The feeding speed should be set as $0.50 \mathrm{~m} / \mathrm{s}$, the tooth roll speed should be set as $34.70 \mathrm{r} / \mathrm{min}$ when the proportion of feeding particle size is between $5.00 \%$ and $20.00 \%$, and the height of material level should be controlled as $0.50 \mathrm{~m} \sim 1.00 \mathrm{~m}$. The maximum feeding speed should be maintained when the proportion of feed size to bulk is less than $5.00 \%$, and the rotation tooth roll speed should be set to 33.00 $\mathrm{r} / \mathrm{min}$ to obtain the optimal crushing and energy saving effect.

It is assumed that the initial feeding speed $v<v_{\max }=0.60 \mathrm{~m} / \mathrm{s}$. The feeding speed should be adjusted to the maximum of 0.60 $\mathrm{m} / \mathrm{s}$, the tooth roll speed should be set to $33.00 \mathrm{r} / \mathrm{min}$ when the proportion of feeding particle size is less than $5.00 \%$, and the height of the material level should be controlled below $1.00 \mathrm{~m}$. The feeding speed should be $0.50 \mathrm{~m} / \mathrm{s}$ and the tooth roll speed should be kept at 33.00 34.70 r/min when the proportion of feed size and the bulk is between $5.00 \%$ and $20.00 \%$. The feeding speed should be set as $0.20 \sim 0.40 \mathrm{~m} / \mathrm{s}$ when the proportion of the feeding particle size is more than $20.00 \%$, and the tooth roller speed is $33.00 \sim 34.70 \mathrm{r} / \mathrm{min}$ to achieve the optimal energy saving crushing.

3) When $Q_{\text {feed }}<Q_{\text {crush }}$, the relationship is:

$$
\int_{0}^{t}\left[\frac{S v \rho}{k_{i}}-\left(v_{l} K_{l} S_{I}+2 \pi r \frac{\omega}{\varphi} S+\frac{\omega}{\varphi} V_{\text {volume }}\right) \rho \varepsilon D_{i} \theta_{i}\right] d t<0
$$

Table 11. The strategy of coordinated speed control crushing

\begin{tabular}{|c|c|c|c|c|}
\hline Mineral state & Relationship & Percentage (\%) & Feeding speed (m/s) & Roller speed (r/min) \\
\hline \multirow{12}{*}{$\begin{array}{l}\text { Mineral } \\
\text { continuity }\end{array}$} & & $<10 \%$ & $0.4 \sim 0.5$ & 33 \\
\hline & $\left\{Q_{\text {feed }}>Q_{\text {crush }}\right.$ & $10 \% \sim 20 \%$ & 0.4 & $33 \sim 34.7$ \\
\hline & $\left(v=v_{\max }\right.$ & $>20 \%$ & $0.2 \sim 0.4$ & $31.3 \sim 33$ \\
\hline & $\int Q_{\text {feed }}>Q_{\text {crush }}$ & $<10 \%$ & Reduce speed & Increase speed \\
\hline & $\left\{\begin{array}{c}\text { v } \\
<v_{\max }\end{array}\right.$ & $>10 \%$ & Reduce speed & $\sim$ \\
\hline & $O=O$ & $>20 \%$ & $0.2 \sim 0.4$ & 33 \\
\hline & $\left\{Q_{\text {feed }}=Q_{\text {crush }}\right.$ & $5 \% \sim 20 \%$ & 0.5 & 34.7 \\
\hline & $v=v_{\max }$ & $<5 \%$ & 0.6 & $33 \sim 36.4$ \\
\hline & $O=O$ & $<5 \%$ & 0.6 & 36.4 \\
\hline & $\left\{Q_{\text {feed }}=Q_{\text {crush }}\right.$ & $5 \% \sim 20 \%$ & 0.5 & $33 \sim 34.7$ \\
\hline & $v<v_{\max }$ & $>20 \%$ & $0.2 \sim 0.4$ & $33 \sim 34.7$ \\
\hline & $\left\{\begin{array}{c}Q_{\text {feed }}<Q_{\text {crush }} \\
v<v_{\max }\end{array}\right.$ & \multicolumn{3}{|c|}{$\begin{array}{l}\text { Increase the speed of feeder step by step. If the efficiency cannot be improved, the tooth roller speed can } \\
\text { be reduced to reduce the over comminution rate. }\end{array}$} \\
\hline $\begin{array}{c}\text { Mineral } \\
\text { discontinuity }\end{array}$ & $\left\{\begin{array}{c}Q_{\text {feed }}>Q_{\text {crush }} \\
v<v_{\max }\end{array}\right.$ & \multicolumn{3}{|c|}{$\begin{array}{l}\text { Reduce the cooperative speed reduction step by step until the shutdown, and it follows the multi } \\
\text { parameter coupling coordinated speed regulation strategy in other conditions. }\end{array}$} \\
\hline
\end{tabular}

\section{CASE STUDY}

The control technology of multiparameter coupling coordinated speed regulation crushing strategy is applied to the crushing station production system of Baorixile open pit mine of Shenhua Group. The energy-saving production of crushing station in open-pit mine has been successfully realized.

\subsection{Case background}

Shenhuabaorixile Energy Co., Ltd. (Shenbao Energy Co., Ltd.) started to develop and construct Baorixile open pit coal
There is a relationship of Eq. (23) based on the actual conditions, due to the influence of objective factors. If the crushing efficiency cannot be improved, the tooth roller speed and feeding speed can be reduced step by step, and the energy consumption of crushing can be reduced.

4) Mineral discontinuity. When $Q_{\text {feed }}>Q_{c r u s h}$, the relationship is:

$$
\int_{0}^{t} \int_{S}^{0}\left[\frac{S v \rho}{k_{i}}-\left(v_{l} K_{l} S_{I}+2 \pi r \frac{\omega}{\varphi} S_{2}+\frac{\omega}{\varphi} V_{\text {volume }}\right) \rho \varepsilon D_{i} \theta_{i}\right] d t d S>0
$$

When the amount of minerals in the silo is decreasing gradually, $Q_{\text {feed }}>Q_{\text {crush }}$ may exist for a certain period of time. The regulation strategy is the same as that when the above minerals are enough, it will not be described here. The feeding speed and the tooth roll speed should be gradually reduced or stopped when $Q_{\text {feed }} \leq Q_{\text {crush }}$, in order to achieve the purpose of energy saving and consumption reduction.

In conclusion, the relationship between $Q_{\text {feed }}$ and $Q_{\text {crush }}$ was analysed according to the simulation results. Summary of multiparameter coupling coordinated speed regulation crushing strategy is shown in Table 11. The material level height can be controlled in the range of $0 \sim 1.00 \mathrm{~m}$ after coordinated speed regulation. The research on the process of mineral crushing was based on the relationship between mineral kinematics and mechanical kinematics. Therefore, the multiparameter coupling coordinated speed regulation crushing strategy is conducive to energy saving operation of crushing station. 
were mainly used to assist production before 2017 in order to reduce the impact of bulk coal on the energy saving effect of raw coal coarse crushing. However, it is difficult to adjust the parameters of the control equipment in time and accurately to ensure the energy saving operation of the crushing station due to the bad working conditions and changeable weather. As a result, the production cost increases and the economic and technical indicators fail to meet the expectations. As shown in Table 12, from 2014 to 2016, the operation of MMD 1250 crushing station was affected by large coal [47].

As shown in Table 12, the maximum number of blocking affected by large coal is 136 . The average time of continuous production affected by crushing station is about 148 hours. In 2014 and 2015, the powder passing rate exceeded 5.5\%. The crushing efficiency is less than $2350 \mathrm{t} / \mathrm{h}$. To sum up, the energy saving production effect of Shenbao energy open pit crushing station is not ideal. This research adopts the multiparameter coupling coordinated speed regulating crushing strategy to design and complete the system transformation of the crushing station of the open pit mine combined with the actual production situation of the industrial site.

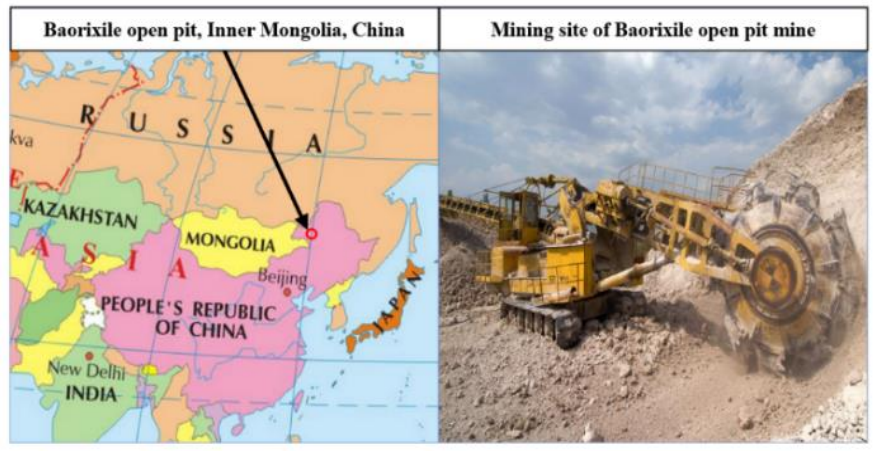

Figure 17. Location and production site of Baorixile open pit mine

Table 12. Production data of MMD 1250 crushing station from 2014 to 2016

\begin{tabular}{cccc}
\hline & & & \\
Project(unit) & $\mathbf{2 0 1 4}$ & $\mathbf{2 0 1 5}$ & $\mathbf{2 0 1 6}$ \\
\hline Blocking times (times) & 69 & 113 & 136 \\
Impact time (h) & 158.70 & 149.10 & 136.10 \\
Repair time (min/times) & 139 & 72 & 66 \\
Operation time (h) & 3900 & 3900 & 3900 \\
Crushing capacity (t) & 8291279 & 8671913 & 9263479 \\
Crushing efficiency (t/h) & 2152 & 2239 & 2348 \\
Powder passing rate (\%) & $5.52 \%$ & $7.39 \%$ & $3.24 \%$ \\
\hline
\end{tabular}

\subsection{Case project implementation}

\subsubsection{Energy saving control target and parameters of crushing} station

A large amount of real-time monitoring data obtained in the production process are compared and analysed combined with the actual production situation of the crushing station in Shenbao energy company's crushing plant. The software and hardware platform of crushing station control system is designed, which is applied to the actual industrial production of crushing station. On the premise of ensuring the safe and stable operation of production, the energy saving operation function of crushing station is realized by multiparameter coupling coordinated speed regulation strategy.
(1) Control target of energy saving operation of crushing station

The common problems affecting the energy saving operation of the crushing station are summarized through a large number research work on the site crushing station.

1) The port on the plate feeder is often blocked by one or several lumps of coal (the pass width is $2540 \mathrm{~mm}$ ).

2) The crown block often appears above the tooth roller of the crushing cavity, and the crown of the crushing tooth roller cannot occlude the material.

3) The speed of the toothed roller of the crusher $(25 \mathrm{rp} / \mathrm{min})$ is too low. According to the statistical analysis of the coal conveying capacity of the belt, it can be concluded that the actual crushing capacity of the crusher cannot meet the requirements of the design capacity of $3500 \mathrm{t} / \mathrm{h}$ when the plate feeder continuously supplies enough coal [48].

4) It is impossible to judge whether the current mechanical and electrical protection devices of the crusher are sensitive and reliable if iron or hard large minerals enter the crusher.

5) The plate feeder and crusher of equipment components of crushing station are in the state of no-load and low load for a long time when the feeding interval of crushing station is long and the continuity is poor, resulting in energy waste.

6) It is difficult to guarantee the reliability of energy saving operation by manually monitoring the production process of crushing station.

The multiparameter coupling coordinated speed regulation control objective of the crushing station is proposed based on the above problems affecting the energy saving operation of the crushing station. It mainly includes the optimization of energy consumption, efficiency, block blocking rate and powder passing rate. The specific control objectives are shown in Table 13

Table 13. Energy saving control target of crushing station production

\begin{tabular}{ccc}
\hline No. & Control objectives & Unit \\
\hline 1 & Energy consumption & Yuan/t \\
2 & Efficiency & $\mathrm{h} / \mathrm{t}$ \\
3 & Block blocking rate & $\%$ \\
4 & Powdering rate & $\%$ \\
\hline
\end{tabular}

(2) Range and adjustment range of control parameters

The control parameters mainly include the height of material level in the crusher cavity, the rotating speed of the crusher tooth roll and the feeding speed of the plate feeder. The particle size of the mineral can be controlled by the material level of the crushing chamber. The specific parameter adjustment range is shown in Table 14.

Table 14. Energy saving control variables and regulation range of crushing station

\begin{tabular}{ccc}
\hline Parameter name (unit) & $\begin{array}{c}\text { Maximum } \\
\text { range }\end{array}$ & $\begin{array}{c}\text { Adjustment } \\
\text { range }\end{array}$ \\
\hline Crushing chamber level & 0.24 & $0 \sim 0.40$ \\
height $(\mathrm{m})$ & 0.20 & $0.50 \sim 1$ \\
Tooth roll speed of & 0.10 & $1 \sim 1.50$ \\
crusher(r/min) & 1.60 & $31.20 \sim 36.30$ \\
Feeding speed(m/s) & 0.21 & $0 \sim 0.50$ \\
\hline
\end{tabular}




\subsubsection{Installation and debugging of level height sensor}

The control parameters of multiparameter coupling coordinated speed regulation crushing are debugged based on the change of material level in crusher cavity in order to reduce the blocking fault of crusher and strengthen the energy saving operation of crusher station.

(1) Experimental principle [49]

The experimental equipment can transmit and receive microwave pulse signals with very low power and very short duration through the antenna system. Transmitting and receiving time can be converted into level signal by electronic components. The measurement and analysis of level echo is not only stable but also accurate. The equipment can be debugged in empty warehouse. The K-band high frequency sensor can be used to measure the height of the material level in the crushing chamber. A good focusing effect can effectively solve the adverse effect of the installation in the crushing chamber during the measurement. The maximum measurement range is $75 \mathrm{~m}$. It is not affected by dust, feeding noise and weather change.

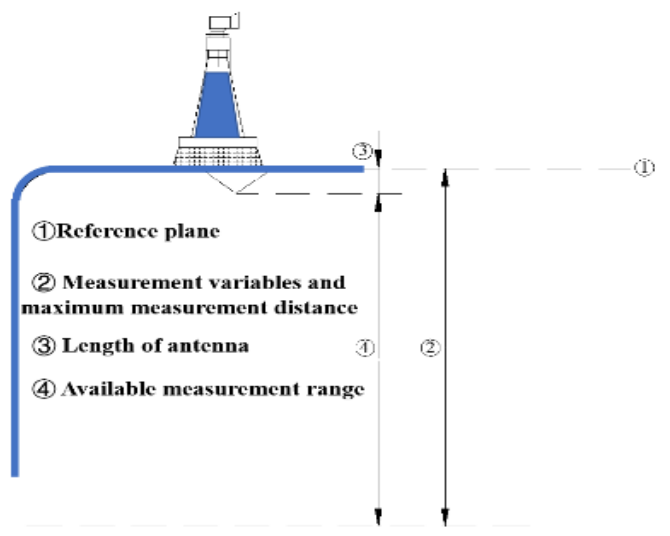

Figure 18. Schematic diagram of measurement process connection and measured medium surface

As shown in Figure 18. An example of the connection between the input parameter measurement process and the surface of the measured medium. The reference plane is the sealing surface of the flange.

\section{(2) Experimental equipment}

As shown in Figure 19, the microwave radar sensor can be installed above the crushing chamber. Its advantage is that the measurement range is $0 \sim 75 \mathrm{~m}$. The temperature can adapt to $200 \sim+350{ }^{\circ} \mathrm{C}$. The accuracy can reach $2 \mathrm{~mm}$. Storage or process containers that accurately measure solid levels, although process conditions can be complex.

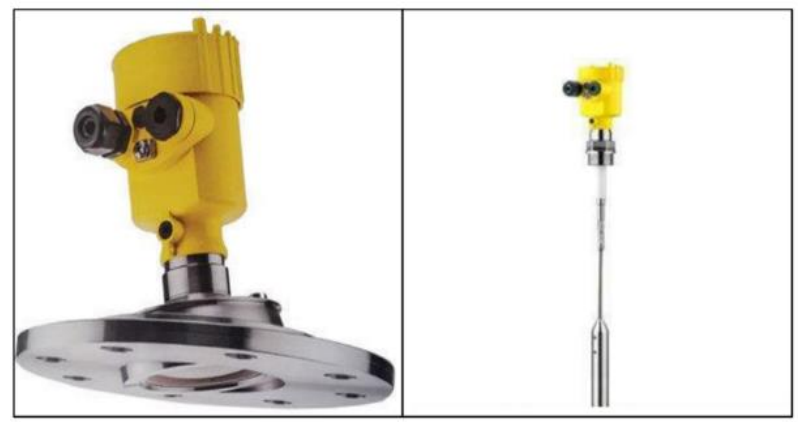

Figure 19. Analog microwave radar sensor
There are many manufacturers of radar sensors for monitoring the material level in the crusher chamber of crushing station. In this experiment, PSSR 68 series of German VEGA company with superior measurement accuracy is selected. The detailed performance parameters are shown in Table 15 .

Table 15. VEGA level radar performance parameters [50]

\begin{tabular}{cc}
\hline Project & Content \\
\hline Application & Liquid, solid media, poor process \\
conditions. \\
Maximum measurement range & $30 \mathrm{~m}$ \\
Antenna/Material & Horn antenna, parabolic \\
antenna/Stainless steel $316 \mathrm{~L}$ \\
Temperature & $-100 \ldots+350^{\circ} \mathrm{C}$ \\
Measurement deviation & $2 \mathrm{~mm}$ \\
Frequency range & K-frequency band \\
Signal output & $4 \ldots 20 \mathrm{~mA} /$ HART_Two wire system $^{-}$T.20mA/HART_Four wire system \\
& Profibus PA Foundation Fieldbus \\
\hline
\end{tabular}

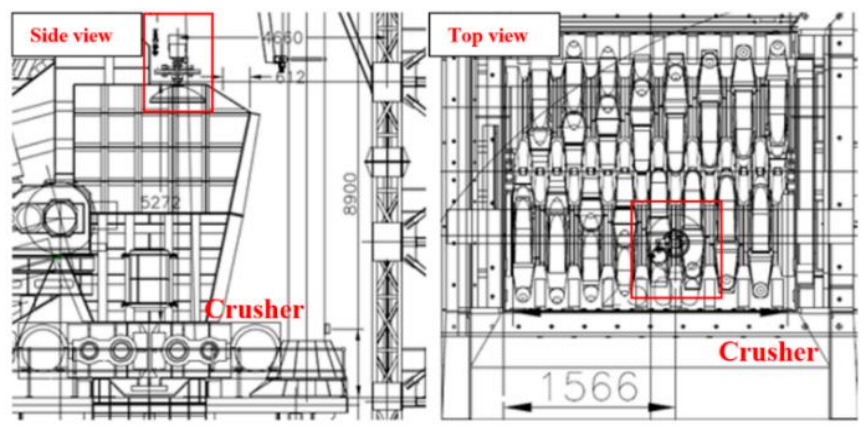

Figure 20. Schematic diagram of installation position of material level radar

(3) Radar equipment installation [51]

It is suggested that the material level monitoring radar in the crusher cavity should be installed directly above the toothed roll outside the crusher through the field installation test and theoretical analysis. Installation height shall be such that the diameter of the microwave coverage area of the radar does not exceed the length of the toothed roller. It is not interfered by the echo generated by the side plate above the crushing chamber. The installation position is shown in Figure 20 above.

\subsection{Application research}

Energy saving control and regulation are based on the current of plate feeder and the height change of material level in crusher cavity. It can adjust the crushing station and improve the energy saving operation of the crushing station Especially when the crusher or plate feeder is under no-load or low load.

As shown in Table 16, the sensor monitors the data. The operation frequency of plate feeder motor is $25 \mathrm{~Hz}$, i.e. the feeding speed is $0.30 \mathrm{~m} / \mathrm{s}$. At this time, the working current distribution of the drive motor is stable, and it is maintained at $274 \mathrm{~A} \sim 302 \mathrm{~A}$. The height of the material level in the crushing chamber usually fluctuates between $0.3 \mathrm{~m}$ and $0.50 \mathrm{~m}$. The drive motor current of the plate feeder is maintained at $120 \mathrm{~A}$ $150 \mathrm{~A}$ when there is less material in the feed bin, and the material level height of the crushing chamber is usually below $0.30 \mathrm{~m}$. 
The current distribution of the driving motor is $312 \mathrm{~A} \sim 345$ A when the operating frequency is $33 \mathrm{~Hz}$, the feeding speed is $0.40 \mathrm{~m} / \mathrm{s}$, and the material level height of the crushing chamber is usually between $0.30 \mathrm{~m}$ and $1.00 \mathrm{~m}$. It is maintained below 120 A when there is little material in the feed bin, and the material level height of the crushing chamber is usually about $0.10 \mathrm{~m}$. It can be seen the current increases correspondingly under high frequency operation, and the height of material level is basically the same. This may be related to the density of unloading and the large amount of material in the feeding bin during high frequency feeding.
The changes of the motor current of the plate feeder and the height of the material level in the crushing chamber corresponding to the no-load and low load state in the production process of the crushing station are divided according to the analysis of the above data. The control parameters of crushing station are modified and verified based on the energy saving operation of crushing station. The regulation adopts the hierarchical regulation rule, that is, the gear will be automatically adjusted up and down when the upper and lower load states meet the conversion, as shown in Table 17 and Table 18.

Table 16. Sensor monitoring data

\begin{tabular}{|c|c|c|c|c|c|c|c|}
\hline \multirow[b]{2}{*}{ No. } & \multicolumn{4}{|c|}{ Double-geared roller crusher } & \multicolumn{2}{|c|}{ Plate feeder } & \multirow{2}{*}{$\begin{array}{c}\text { Crushing } \\
\text { Operating efficiency } t / h\end{array}$} \\
\hline & $\begin{array}{c}\text { Level height } \\
\text { m }\end{array}$ & $\begin{array}{c}\text { Motor current } \\
\text { A }\end{array}$ & $\begin{array}{c}\text { Oil temperature } \\
{ }^{\circ} \mathrm{C}\end{array}$ & $\begin{array}{c}\text { Roller speed } \\
\text { r/min }\end{array}$ & $\begin{array}{c}\text { Motor current } \\
\text { A }\end{array}$ & $\begin{array}{c}\text { Feeding speed } \\
\text { Hz }\end{array}$ & \\
\hline 1 & 0.34 & 8 & 55 & 33 & 289 & 25 & 2150 \\
\hline 2 & 0.48 & 10 & 68 & 33 & 282 & 25 & 2320 \\
\hline 3 & 0.42 & 10 & 70 & 33 & 289 & 25 & 2250 \\
\hline 4 & 0.26 & 10 & 65 & 33 & 276 & 25 & 2110 \\
\hline 5 & 0.39 & 10 & 57 & 33 & 279 & 25 & 2105 \\
\hline 6 & 0.22 & 9 & 50 & 33 & 274 & 25 & 2055 \\
\hline 7 & 0.23 & 8 & 48 & 33 & 275 & 25 & 2050 \\
\hline 8 & 0.40 & 8 & 49 & 33 & 299 & 25 & 2235 \\
\hline 9 & 0.16 & 8 & 46 & 33 & 302 & 25 & 2150 \\
\hline 10 & 0.39 & 8 & 45 & 33 & 188 & 33 & 2700 \\
\hline 11 & 0.17 & 8 & 43 & 33 & 323 & 33 & 2655 \\
\hline 12 & 0.20 & 10 & 56 & 33 & 331 & 33 & 2653 \\
\hline 13 & 0.41 & 10 & 58 & 33 & 338 & 33 & 2750 \\
\hline 14 & 1.40 & 23 & 96 & 33 & 375 & 33 & 1900 \\
\hline 15 & 1.03 & 19 & 78 & 33 & 335 & 33 & 2285 \\
\hline 16 & 0.41 & 13 & 75 & 33 & 325 & 33 & 2355 \\
\hline 17 & 0.37 & 11 & 60 & 33 & 314 & 33 & 2430 \\
\hline 18 & 0.43 & 12 & 64 & 33 & 312 & 33 & 2550 \\
\hline 19 & 0.31 & 10 & 59 & 33 & 198 & 33 & 2760 \\
\hline 20 & 0.38 & 9 & 54 & 33 & 188 & 33 & 2730 \\
\hline 21 & 0.17 & 8 & 46 & 33 & 177 & 33 & 2640 \\
\hline
\end{tabular}

Table 17. Hierarchical adjustment standard based on minimum energy loss of crushing station (from high to low)

\begin{tabular}{cccccccc}
\hline $\begin{array}{c}\text { Load } \\
\text { status }\end{array}$ & \multirow{2}{*}{ Gear } & $\begin{array}{c}\text { Feeder } \\
\text { current }(\mathbf{A})\end{array}$ & $\begin{array}{c}\text { Cavity level } \\
\text { height }(\mathbf{m})\end{array}$ & \multicolumn{2}{c}{ Feed frequency (Hz) } & \multicolumn{2}{c}{ Roll speed (rp/min) } \\
Before correction & After correction & Before correction & After correction \\
\hline Low load & 1 & $(120,150)$ & $(0,0.3)$ & 25 & 10 & 33 & 31.3 \\
No load & 0 & $(0,100)$ & 0 & 20 & 5 & 33 & 31.3 \\
\hline
\end{tabular}

Table 18. Hierarchical adjustment standard based on the minimum energy loss of crushing station (from low to high)

\begin{tabular}{ccccccc}
\hline $\begin{array}{c}\text { Load } \\
\text { status }\end{array}$ & \multirow{2}{*}{ Gear } & $\begin{array}{c}\text { Feeder } \\
\text { current (A) }\end{array}$ & $\begin{array}{c}\text { Cavity level } \\
\text { height (m) }\end{array}$ & \multicolumn{2}{c}{ Feed frequency (Hz) } & \multicolumn{2}{c}{ Roll speed (rp/min) } \\
Before correction & After correction & Before correction & After correction \\
\hline Low load & 1 & $(90,120)$ & $(0.3,0.5)$ & 5 & 10 & 31.3 \\
No load & 2 & $(120,280)$ & $(0.3,0.5)$ & 10 & 25 & 36.4 \\
\hline
\end{tabular}

\subsection{Application effect analysis}

The multiparameter coupling coordinated speed regulating crushing strategy has carried out many industrial verification and experimental studies since the production system of Baorixile open-pit crushing station was put into use in early 2017. The operation effect of crushing station shows that: The number of times of no-load or low load of crusher can be reduced based on the dual multiparameter coupling coordinated speed control strategy, which is conducive to energy saving operation of crushing station. The energy saving operation of the crushing station is realized by automatically switching the control parameter setting value of the crushing station when the feed flow is too small or the discontinuity is strong. The energy saving control of crushing process in crushing station is realized by the application of multiparameter coupling and coordinated speed regulation. The operation effect of crushing station has been significantly improved.

Taking MMD 1250 crushing station as an example. The operation indexes of the multiparameter coupling coordinated speed regulation crushing strategy (2017) and the manual operation control method (2014-2016 three-year average) are calculated respectively. The application effect is shown in Table 19. 
Table 19. Application effect comparison between intelligent control and artificial control

\begin{tabular}{|c|c|c|c|c|}
\hline \multirow{2}{*}{ Index } & \multicolumn{2}{|c|}{ Year } & \multirow{2}{*}{ Change } & \multirow{2}{*}{ Remarks } \\
\hline & (2014-2016) & 2017 & & \\
\hline Blockage (times/ years) & 106.00 & 68.00 & $-36.00 \%$ & Reduced blockages number \\
\hline Impact time(h) & 148.00 & 46.00 & $-69.00 \%$ & Reduced impact time \\
\hline Treatment time (min/times) & 92.00 & 40.00 & $-57.00 \%$ & Reduced treatment times \\
\hline Running time(h) & 3900.00 & 4000.00 & $+2.56 \%$ & Increase operation time \\
\hline Crushing capacity (Mt) & 8.73 & 10.95 & $+25.43 \%$ & Increase crushing capacity \\
\hline Crushing efficiency $(\mathrm{t} / \mathrm{h})$ & 2247.00 & 2737.00 & $+21.80 \%$ & Increase efficiency \\
\hline Powder passing rate $(\%)$ & $5.38 \%$ & $2.51 \%$ & $-53.35 \%$ & Reduced powder passing rate \\
\hline
\end{tabular}

As shown in Table 19, the relevant data shows that the application of multiparameter coupling coordinated speed regulation crushing strategy has an obvious effect on energy saving operation of crushing station, reducing blocking times and improving efficiency. Manual control is not only difficult to control the real-time operation state of crushing station, but also more difficult to realize the energy saving operation of crushing station. The phenomenon of high powder passing rate and low efficiency often occurs, which seriously affects the economic benefits of the mine. As shown in Table 19, the multiparameter coupling and coordinated speed regulation crushing strategy is adopted, and the powder passing rate is controlled within $3.00 \%$. It is reduced by $53.35 \%$ compared with manual operation control. The crushing efficiency of crushing station increased by $21.80 \%$. The number of blocking was reduced from 106.00 times to 68.00 times, the time of single treatment was saved by 52.00 minutes, and the annual operation time was increased by about 100.00 hours. The energy saving of multiparameter coupling coordinated speed regulation strategy is about $41.00 \%$ compared with manual operation control, which is better than the previous research results of single parameter optimization of crushing station [21-25]. It is verified that the multiparameter coupling coordinated speed regulation crushing strategy conforms to the code for design of open pit mining engineering (GB 509702014) [52]. The above analysis shows that the energy saving operation of the crushing station can be improved obviously by adopting the multiparameter coupling coordinated speed regulation crushing strategy in the production process of the crushing station. It improves the economic benefits of the enterprise. This strategy has a broad application prospect in mining industry.

\section{CONCLUSIONS}

In this study, the multiparameter coupling coordinated speed regulation crushing strategy can improve the energy saving operation of crushing station, and application effect of this strategy is verified by the actual production. The primary conclusions of the study are as follows:

(1) The operation process of crushing station is analyzed based on the discrete element method, particle contact model, multiscale viscous particle model and many related research methods. A multiparameter coupling coordinated speed regulation crushing strategy is established combined with the crusher model, simulation parameters, multiparameter coupling relationship and speed regulation analysis.

(2) The multiparameter coupling coordinated speed regulation crushing strategy is verified by the actual production of Shenhua Energy open pit crushing station. The application results show that compared with the manual operation control, the crushing efficiency of the crushing station is increased by $21.80 \%$, the powder passing rate is reduced by $53.35 \%$, and the operation energy saving of the crushing station is about $41.00 \%$. The energy saving effect of multiparameter optimization is better than that of single parameter.

(3) This research provides a novel theoretical basis for the multiparameter coupling coordinated speed regulation crushing to improve the energy saving operation of crushing station. This strategy has a broad application prospect in the crushing station of open pit mining.

\section{REFERENCES}

[1] Todeschini, S., Papiri, S., Ciaponi, C. (2014). Stormwater quality control for sustainable urban drainage systems. International Journal of Sustainable Development and Planning, 9(2): 196-210. https://doi.org/10.2495/SDP-V9-N2-196-210

[2] Yuan, Q.Q., Cheng, C.F., Wang, J.Y., Zhu, T.T. Wang, K. (2020). Inclusive and sustainable industrial development in China: An efficiency-based analysis for current status and improving potentials. Applied Energy, 268: 114876.

https://doi.org/10.1016/j.apenergy.2020.114876

[3] Wang, C., Hong, J. (2020). Empirical analysis on the sustainable development of China's outward foreign direct investment from the perspective of economic institution. International Journal of Sustainable Development and Planning, 15(3): 369-375. https://doi.org/10.18280/ijsdp.150314

[4] Asr, E.T., Kakaie, R., Ataei, M., Mohammadi, M.R. (2019). A review of studies on sustainable development in mining life cycle. Journal of Cleaner Production, 229: 213-231. https://doi.org/10.1016/j.jclepro. 2019.05.029

[5] Yu, S.W., Gao, S.W., Sun, H. (2016). A dynamic programming model for environmental investment decision- making in coal mining. Applied Energy, 166: 273-281. https://doi.org/10.1016/j.apenergy.2015.09.099

[6] Alzoubi, M.A., Zueter, A., Rouquette, A.N., Agus, P.S. (2019). Freezing on demand: A new concept for mine safety and energy savings in wet underground mines. International Journal of Mining Science and Technology, 29(4): 621-627. https://doi.org/10.1016/j.ijmst.2019.06.015

[7] Monteiro, N.B., Silva, E.A., Neto, J.M. (2019). Sustainable development goals in mining. Journal of Cleaner Production, 228: 509-520. https://doi.org/10.1016/j.jclepro.2019.04.332

[8] Cai, W., Liu, C.H., Lai, K.H., Li, L., Jorge, C., Hu, L.K. (2019). Energy performance certification in mechanical 
manufacturing industry: A review and analysis. Energy Conversion and Management, 186: 415-432. https://doi.org/10.1016/j.enconman.2019.02.041

[9] Cai, W., Lai, K.H., Liu, C.H., Wei, F.F., Minda, M., Jia, S., Jian, Z.G., Lv, Li. (2019). Promoting sustainability of manufacturing industry through the lean energy saving and emission-reduction strategy. Science of The Total Environment, 665:

23-32. https://doi.org/10.1016/j.scitotenv.2019.02.069

[10] Lin, B.Q., Zhu, J.P. (2019). Impact of energy saving and emission reduction policy on urban sustainable development: Empirical evidence from China. Applied Energy, 239:

12-22. https://doi.org/10.1016/j.apenergy.2019.01.166

[11] Barabady, J., Kumar, U. (2008). Reliability analysis of mining equipment: A case study of a crushing plant at Jajarm Bauxite Mine in Iran. Reliability Engineering \& System Safety, 93(4): 647-653. https://doi.org/10.1016/j.ress.2007.10.006

[12] Albin, G., Gauti, A., Erik, H., Magnus, E. (2018). Diagnostics of cone crusher feed segregation using power draw measurements. Minerals Engineering, 127: 15-21. https://doi.org/10.1016/j.mineng. 2018.07.008

[13] Rahimdel, M.J., Ataei, M. (2014). Application of analytical hierarchy process to selection of primary crusher. International Journal of Mining Science and Technology, 24(4): 519-523. https://doi.org/10.1016/j.ijmst.2014.05.016

[14] Yang, X., Desai, C.S., Daouadji, A., Armin, W.S., Liu, H.L., Hossam, A.N. (2020). Grain crushing in geoscience materials--Key issues on crushing response, measurement and modeling: Review and Preface. Geoscience Frontiers, 11(2): 363-374. https://doi.org/10.1016/j.gsf.2019.11.006

[15] Wang, G.R., Huang, R., Zhong, L., Wang, L.Z., Zhou, S.W., Liu, Q.Y. (2019). An optimal design of crushing parameters of marine gas hydrate reservoirs in solid fluidization exploitation. Natural Gas Industry B, 6(3): 257-261. https://doi.org/10.1016/j.ngib.2018.10.006

[16] André, F.P., Tavares, L.M. (2020). Simulating a laboratory-scale cone crusher in DEM using polyhedral particles. Powder Technology, 372: 362-371. https://doi.org/10.1016/j.powtec.2020.06.016

[17] Rajmeny, P., Shrimali, R. (2019). Use of radar technology to establish threshold values of blast vibrations triggering sliding of geological faults at a leadzinc open pit mine. International Journal of Rock Mechanics and Mining Sciences, 113: 142-149. https://doi.org/10.1016/j.ijrmms.2018.12.004

[18] Kenneth, H., Päivi, K.R., Pirita, H., Kati, V., Ali, E. (2017). Global energy consumption due to friction and wear in the mining industry. Tribology International, 115: 116-139. https://doi.org/10.1016/j.triboint.2017.05.010

[19] Ranängen, H., Lindman, Å. (2017). A path towards sustainability for the Nordic mining industry. Journal of Cleaner Production, 151: 43-52. https://doi.org/10.1016/j.jclepro. 2017.03.047

[20] Carbajo, R., Cabeza, L.F. (2019). Sustainability and social justice dimension indicators for applied renewable energy research: A responsible approach proposal. Applied $\quad$ Energy, 113429. https://doi.org/10.1016/j.apenergy.2019.113429

[21] Numbi, B.P., Zhang, J., Xia, X. (2014). Optimal energy management for a jaw crushing process in deep mines.
Energy,

68:

$337-348$

https://doi.org/10.1016/j.energy.2014.02.100

[22] Terva, J., Kuokkala, V.T., Valtonen, K., Pekka, S. (2018). Effects of compression and sliding on the wear and energy consumption in mineral crushing. Wear, 398-399: 116-126. https: //doi.org/10.1016/j.wear.2017.12.004

[23] Singh, R.R., Chelliah, T.R. (2017). Enforcement of costeffective energy conservation on single-fed asynchronous machine using a novel switching strategy. Energy, 126: 179-191. https://doi.org/10.1016/j.energy.2017.03.003

[24] Deng, Y., Chen, M., Jin, Y., Zou, D.W. (2016). Theoretical analysis and experimental research on the energy dissipation of rock crushing based on fractal theory. Journal of Natural Gas Science and Engineering, 33: 231-239. https://doi.org/10.1016/j.jngse.2016.05.020

[25] Daniel, L., Ron, Z. (2014). Assessing the energy efficiency of a jaw crusher. Energy, 74: 119-130. https://doi.org/10.1016/j.energy.2014.04.036

[26] Xiao, W.X. (2012). Evolution research of major hazards in Shenhua Baorixile Open Coal Mine. Liaoning Technical University.

[27] Zhao, Y.X., Wang, Y.D. (2012). An overview of theory and equipments of mineral processing fragmentation. China Mining Magazine, 21(11): 103-105+109. https://doi.org/10.17863/CAM.1564

[28] Ovchinnikov, P.F., SidenkoG, S.N., Semchenko, D. (1998). Theory and practice of crushing, separation, mixing and compaction processes. Glass\&Ceramics, 55(1-2): 60-61. https://doi.org/10.1007/BF03180151

[29] Sedinin, D.F., Teslya, A.S., Ustimov, V.K., Eryukhin, N.V., Lagutin, P.V. (2012). Reconstruction of the crushing plant with increasing of capacity and construction of homogenization storehouse of finecrushed ore. Fems Microbiology Letters, 109(2-3): 257 261. 6968.1993.tb06177.x

[30] Xiong, Y. (2016). Application of simulation technology in mechanical design and manufacture. Electronic Technology \& Software Engineering, (15): 82.

[31] Li, H., McDowell, G., Lowndes, I. (2014). Discrete element modelling of a rock cone crusher. Powder Technology, 2014, 263: 151-158. https://doi.org/10.1016/j.powtec.2014.05.004

[32] Wang, P., Arson, C. (2016). Discrete element modeling of shielding and size effects during single particle crushing. Computers and Geotechnics, 78: 227-236. https://doi.org/10.1016/j.compgeo.2016.04.003

[33] Refahi, A., Mohandesi, J.A., Rezai, B. (2010). Discrete element modeling for predicting breakage behavior and fracture energy of a single particle in a jaw crusher. International Journal of Mineral Processing, 94(1-2): 8391. https://doi.org/10.1016/j.minpro.2009.12.002

[34] Zhu, S., Wu, Y., Lu, L. (2017). Fragmentation evolution and fractal characteristics of deep rocks by lab compression-shear tests. Journal of Testing and Evaluation, 46(4): 20160491. https://doi.org/10.1520/JTE20160491

[35] Wang, L., Gao, Q. (2007). Fragmentation distribution prediction of rock based on damage energy dissipation. Chinese Journal of Rock Mechanics and Engineering, 26(6): 1202-1211. https://doi.org/10.1007/s10870-0079222-9

[36] Orford, J.D., Whalley, W.B. (1983). The use of the 
fractal dimension to quantify the morphology of irregular-shaped particles. Sedirnentology, 30: 655-668. https://doi.org/10.1111/j.1365-3091.1983.tb00700.x

[37] Chen, T.P. (2013). Research on character of centrallypivoted structure of vertical screw shaft in the L screw ship unloader. Wuhan: Wuhan University of Technology.

[38] Helinski, M., Fahey, M., Fourie, A. (2010). Coupled twodimensional finite element modelling of mine backfilling with cemented tailings. Canadian Geotechnical Journal, 47(11): 1187-1200. https://doi.org/10.1139/t10-020

[39] Margarida, M., Pedro, M., Paulo, F., Hamid M.L. (2012). Compliant contact force models in multibody dynamics: Evolution of the Hertz contact theory. Mechanism and Machine Theory, 53: 99-121. https://doi.org/10.1016/j.mechmachtheory.2012.02.010

[40] Greaves, G.N., Greer, A.L., Lakes, R.S., Rouxel, T. (2011). Poisson's ratio and modern materials. Nature Materials, 10 : 823-836. https://doi.org/10.1038/nmat3134

[41] Zhang, G.Y., Cheng, P. (2018). Effect factors analysis of south end slope stability in the second mining area of Heidaigou open-pit coal mine. Opencast Mining Technology, 033(004): 67-70.

[42] Sancho, P.J. (2009). Surface plasmon resonance broadening of metallic particles in the quasi-static approximation: A numerical study of size confinement and interparticle interaction effects. Nanotechnology, 20(23): 235706. https://doi.org/10.1088/09574484/20/23/235706

[43] Guermond, J.L., Minev, P. (2015). High-order time stepping for the Incompressible Navier--stokes equations. Siam Journal on Scientific Computing, 37(6): A2656A2681. https://doi.org /10.1137/140975231

[44] Tang, H.L. (2013). Dynamics of price Reyleigh equation with time delay. Journal of Shanxi University (Natural Science Edition), 36(2): 143-148.

[45] Sanzana, P., Jankowfsky, S., Branger, F., Braud, I., Vargas, X., Hitschfeld, N., Gironás, J. (2013). Computer- assisted mesh generation based on hydrological response units for distributed hydrological modelling. Computers \& Geosciences, 57: 32-43. https://doi.org/10.1016/j.cageo.2013.02.006

[46] Jie, Z., Zhou, X. (2001). Study on mathematical model of feed quantity sensor measuring. Transactions of The Chinese Society of Agricultural Machinery, 5: 53-55.

[47] Xiao, W.X. (2012). Evaluation research of major hazards in Shenhua Baorixile open coal mine. Liaoning Technical University.

[48] Wang, J.W. (2018). Research on application technology of semi-continuous coal mining system with self-move crusher in Bao Rixile open-pit coal mine. China University of Mining and Technology.

[49] Germany VEGA. VEGA Operation manual of level meter. http://vega.56tv.com.cn/.

[50] Kim, J.H., Kim, D.G., Shin, J.H., Lee, S.W., Hong, K.S. (2005). Hand gesture recognition system using fuzzy algorithm and RDBMS for post PC. Lecture Notes in Computer Science, 3614: 170-175. https://doi.org/10.1007/11540007_21

[51] Sun, K.Y. (2018). Application of monitoring technology in primary crushing station of Shenhua energy company. Opencast Mining Technology, 33(5): 86-88+91. https://doi.org/10.13235/j.cnki.ltcm.2018.05.022

[52] GB 50970-2014 (2014). Code for design of opencast mining engineering of decorative stone mine.

[53] Tavarez, F.A., Plesha, M.E. (2007). Discrete element method for modelling solid and particulate materials. International Journal for Numerical Methods in Engineering, $\quad 70(4)$ : 379-404. https://doi.org/10.1002/nme.1881

[54] Lu, Y., Leinonen, T. (2005). Solution and simulation of position-orientation for multi-spatial 3-RPS parallel mechanisms in series connection. Multibody System Dynamics, 14(1): 47-60. https://doi.org/10.1007/s11044005-1355-z 